\title{
A new approach to the analysis of Type 1 non-uniqueness of the ITS-90 above $0{ }^{\circ} \mathrm{C}$
}

\author{
Sonia Gaita ${ }^{1, *}$ and Georges Bonnier ${ }^{2}$ \\ ${ }^{1}$ Formerly: National Institute of Metrology (INM), Bucharest, Romania \\ ${ }^{2}$ Formerly: Institut National de Métrologie - Laboratoire National de métrologie et d'essais/ Conservatoire National des Arts et \\ Métiers (INM - LNE/CNAM), La Plaine Saint-Denis, France
}

Received: 15 March 2017 / Accepted: 15 November 2017

\begin{abstract}
The Type 1 non-uniqueness (NU-1) is the difference between interpolated values at the same temperature in the resistance thermometer subranges of the International Temperature Scale of 1990 (ITS-90) that overlap. The paper argues for a method of evaluating the NU-1 at a given temperature which considers all subranges of the Scale that contain the respective temperature, not only combinations of two, and it proposes mathematical models to determine the values of NU-1 for temperatures above $0{ }^{\circ} \mathrm{C}$. The paper demonstrates that NU-1 is not the right contributor to the uncertainty associated with the realisation of the ITS-90. Therefore, a new concept of Correction for the Type 1 non-uniqueness of the Scale, $C_{\mathrm{NU}-1}$, is introduced and its mathematical model is established. Also, the estimate of $C_{\mathrm{NU}-1}$ and its standard uncertainty are defined and they are assessed through statistical analysis. The values of standard uncertainty determined by the novel methodology do not exceed $0.26 \mathrm{mK}$ and they are smaller than the values given in the specific Guides developed by the Consultative Committee for Thermometry. The proposed models allow authors to single out and analyse the factors that generate Type 1 non-uniqueness of the Scale and influence its value.
\end{abstract}

Keywords: International Temperature Scale of 1990 (ITS-90) / Type 1 non-uniqueness of the ITS-90 / measurement uncertainty / standard platinum resistance thermometer (SPRT)

\section{Introduction}

The Type 1 non-uniqueness, hereafter noted as NU-1, emerged as a major concern of thermometry community during the process of establishing the International Temperature Scale of 1990 (ITS-90) [1]. Unlike its predecessors, the current Scale comprises several subranges that overlap, each of them with a distinct definition of temperature $T_{90}$. At a given temperature, the interpolated values using the specified equations for the overlapping subranges may or may not be consistent with each other. The numerical difference between these values [1] is currently called the Type 1 non-uniqueness $[2,3]$.

Understanding of the concept, hereafter called, indicatively, Type 1 non-uniqueness of the Scale, is important when calibrations according to the ITS-90 are performed using standard platinum resistance thermometers (SPRTs). The Type 1 non-uniqueness of the Scale is one of the factors that influence the results of interpolations made between fixed points in the SPRT

* Corresponding author. sonia.gaita@temperature.ro subranges that overlap. Therefore, the correction of its effect must be one of the input quantities in the mathematical models of interpolations and the uncertainty of this correction must be one of the components of the uncertainty in realising the ITS-90 between fixed points. In their turn, the interpolated values - along with the values determined at the fixed points - and their uncertainties are the sources of traceability for all measurements made between $14 \mathrm{~K}$ and $962{ }^{\circ} \mathrm{C}$; in other words, they are the references for the calibration hierarchies, where each measurement result is related to the previous result and the measurement uncertainty increases gradually.

The first study available on Type 1 non-uniqueness (formerly called subrange inconsistency) is the pioneering work of Hill and Bedford [4] performed during the development process of the ITS-90. In this study, a procedure for minimizing the internal inconsistency of the Scale by adjusting the temperatures assigned to the fixed points is described. Subsequently, Crovini revealed [5] the final adjustments made by the designers of the ITS-90 to obtain the highest level of agreement between the definitions of subranges that overlap. 
Starting in the early 90 's, the thermometry community was very interested in Type 1 non-uniqueness above $0{ }^{\circ} \mathrm{C}$. The studies were mainly concerned [6-8] with determining the values of the Type 1 non-uniqueness for combinations of two overlapping subranges, using a larger or a smaller set of SPRTs calibrated at the fixed points. For each such combination, the NU-1 values were calculated as differences between the interpolated temperatures within the two sub-ranges that form the pair. In addition, Strouse [6] presented descriptive statistics (but not the average and the sample standard deviation) for all of the 15 combinations of two overlapping subranges above $0^{\circ} \mathrm{C}$.

In a paper that brought significant contributions to the topic [9], Zhiru Kang et al. studied the subranges pair $0{ }^{\circ} \mathrm{C}$ to $420^{\circ} \mathrm{C}$ and $0{ }^{\circ} \mathrm{C}$ to $660^{\circ} \mathrm{C}$ using various methods, from statistical analysis to Lagrange interpolation. The authors have derived a simple formula for calculating the NU-1 values based on the $c$ coefficient of the deviation function in the subrange $0^{\circ} \mathrm{C}$ to $660^{\circ} \mathrm{C}$. Moreover, they have developed the first method to evaluate the standard uncertainty associated with NU-1. This paper was followed by the work of White and Strouse [10], who investigated the same pair of two subranges, $0{ }^{\circ} \mathrm{C}$ to $420^{\circ} \mathrm{C}$ and $0{ }^{\circ} \mathrm{C}$ to $660^{\circ} \mathrm{C}$. In their study, a polynomial curve was derived of the standard deviations calculated for the differences between the two subranges. The formula was taken in the Document CCT/ 08-19/rev [11] and the Guide to the Realization of the ITS90 [3] to estimate standard uncertainties of NU-1 between $0^{\circ} \mathrm{C}$ and $420^{\circ} \mathrm{C}$. Also, the authors have derived [10] mathematical expressions of NU-1 for combinations of two subranges between $84 \mathrm{~K}$ and $660^{\circ} \mathrm{C}$. Later, Zhiru Kang et al. $[12,13]$ extended the investigation of Type 1 nonuniqueness initiated in [9] to the other 14 pairs of overlapping subranges above $0^{\circ} \mathrm{C}$. The authors have derived simple formulas for the calculation of the maximum NU-1 values in the case of 11 of the subranges pairs under study.

Over twenty-five years have passed since the ITS-90 was adopted, but the issue of its intrinsic Type 1 nonuniqueness has not been fully clarified yet. There is limited coverage in the specific literature regarding the definition and quantification of its effect on interpolated values. All of the papers published so far [4-18] have considered and studied exclusively combinations of two subranges that overlap, the differences associated with each pair being regarded as estimates of the effect.

This article presents a different approach. A distinction is made between the general concept of Type 1 nonuniqueness of the Scale and its measure defined in [1-3]: Type 1 non-uniqueness. The paper argues for a method of evaluating the Type 1 non-uniqueness between all subranges that overlap, not only between two of them. Consequently, the notions of SimpleType 1 non-uniqueness and Combined Type 1 non-uniqueness are advanced and mathematical models for combinations of two and, respectively, more subranges that overlap are developed. Analytical expressions of the Simple Type 1 non-uniqueness for the 15 pairs of subranges that overlap above $0^{\circ} \mathrm{C}$ are derived.

The paper demonstrates that Type 1 non-uniqueness is not the right contributor to the uncertainties of the interpolated values in the SPRT subranges of the ITS-90.
For this reason, the new concept of Correction for the Type 1 non-uniqueness of the Scale, $C_{\mathrm{NU}-1}$, is introduced and the analytical expressions for the 15 possible cases are derived. The best estimate available of the effect of the Type 1 nonuniqueness of the Scale on the interpolated values and its standard uncertainty are defined. In addition, they are evaluated through statistical analysis of the data derived from the results of the key comparison CCT-K3 [19].

A basic characteristic of all the proposed mathematical models in this study is the expression of the output quantity as function of the deviations determined at the fixed points. This form of the equations allows one to single out and analyse the factors that generate the Type 1 nonuniqueness of the Scale and influence its value.

The article is organised as follows. Starting from the interpolation equations defined in ITS-90, the mathematical models for the calculation of the Simple Type 1 nonuniqueness and the Combined Type 1 non-uniqueness are proposed in Section 2. The concept of Correction for the Type 1 non-uniqueness of the Scale, along with its mathematical model, are introduced in Section 3. Section 4 concentrates on the data analysis and the discussing the results, including their comparison with results of other studies. In Section 5, a set of remarks and comments regarding the sources of Type 1 non-uniqueness of the Scale are presented. Section 6 gathers certain concluding remarks.

\section{Sorts of Type 1 non-uniqueness}

Within the temperature range $0^{\circ} \mathrm{C}$ to $961,78^{\circ} \mathrm{C}$, which is the scope of this article, ITS-90 defines the temperature $T_{90}$ using SPRTs calibrated at specified sets of defining fixed points [1]. $T_{90}$ is determined in terms of the resistances ratio:

$$
W\left(T_{90}\right)=R\left(T_{90}\right) / R(273.16 \mathrm{~K}),
$$

by means of a continuous reference function $W_{\mathrm{r}}\left(T_{90}\right)$, hereafter denoted by $W_{\mathrm{r}}$, with the coefficients provided in the ITS-90, and by means of a deviation function [1]

$$
\Delta W\left(T_{90}\right)=W\left(T_{90}\right)-W_{r}\left(T_{90}\right)
$$

The form of the deviation function, hereafter designated by $\Delta W$, is specified for each subrange [1].

There are six SPRT subranges of ITS-90 that overlap above $0{ }^{\circ} \mathrm{C}$ (including the subrange $-38.8344^{\circ} \mathrm{C}$ to $29.7646^{\circ} \mathrm{C}$ ). They are presented in Table 1 together with the sets of fixed points and the deviation functions used to define the temperature $T_{90}$. (The full range $0{ }^{\circ} \mathrm{C}$ to $961.78^{\circ} \mathrm{C}$ is excluded from analysis because it has the same definition for $T_{90}$ as the subrange $0^{\circ} \mathrm{C}$ to $660.323^{\circ} \mathrm{C}$ in their region of overlap.) Although the analytical expressions of certain deviation functions are identical (see Table 1), the values of their coefficients are not equal because they are determined by calibration at different fixed points.

\subsection{The Simple Type 1 non-uniqueness}

Let us first consider the straightforward case of Type 1 nonuniqueness between two overlapping subranges, hereafter called Simple Type 1 non-uniqueness. The six subranges 
Table 1. Definition of $T_{90}$ in the SPRT subranges of the ITS-90 that overlap above $0^{\circ} \mathrm{C}$.

\begin{tabular}{llll}
\hline $\begin{array}{l}\text { SPRT subranges that } \\
\text { overlap above } 0{ }^{\circ} \mathrm{C}\end{array}$ & Symbol & $\begin{array}{l}\text { Deviation } \\
\text { function } \Delta W\end{array}$ & Fixed points \\
\hline $0^{\circ} \mathrm{C}$ to $29.7646^{\circ} \mathrm{C}$ & $(\mathrm{Ga})$ & $a(W-1)$ & $\mathrm{TPW}^{\mathrm{a}}$ and $\mathrm{MP}^{\mathrm{b}}$ of Ga \\
$0^{\circ} \mathrm{C}$ to $156.5985^{\circ} \mathrm{C}$ & $(\mathrm{In})$ & As for $(\mathrm{Ga})$ & $\mathrm{TPW}$ and $\mathrm{FrP}^{\mathrm{c}}$ of In \\
$0^{\circ} \mathrm{C}$ to $231.928^{\circ} \mathrm{C}$ & $(\mathrm{Sn})$ & $a(W-1)+b(W-1)^{2}$ & $\mathrm{TPW}$ and FrPs of In and Sn \\
$0^{\circ} \mathrm{C}$ to $419.527{ }^{\circ} \mathrm{C}$ & $(\mathrm{Zn})$ & As for $(\mathrm{Sn})$ & TPW and FrPs of Sn and $\mathrm{Zn}$ \\
$0^{\circ} \mathrm{C}$ to $660.323^{\circ} \mathrm{C}$ & $(\mathrm{Al})$ & $a(W-1)+b(W-1)^{2}+c(W-1)^{3}$ & TPW and FrPs of Sn, Zn, and Al \\
$-38.8344{ }^{\circ} \mathrm{C}$ to $29.7646{ }^{\circ} \mathrm{C}$ & $(\mathrm{Hg})$ & As for $(\mathrm{Sn})$ & TPW, TP of $\mathrm{Hg}$ and MP of Ga \\
\hline
\end{tabular}

a Triple point of water.

b Melting point.

${ }^{\mathrm{c}}$ Freezing point.

d Triple point.

Table 2. Pairs of subranges that overlap above $0{ }^{\circ} \mathrm{C}$.

\begin{tabular}{|c|c|c|}
\hline Temperature region & $\begin{array}{l}\text { SPRT subranges that } \\
\text { overlap above } 0^{\circ} \mathrm{C}\end{array}$ & Pairs of overlapping subranges \\
\hline $\begin{array}{l}\text { Region } 1(\mathrm{R} 1) \text { : } \\
0^{\circ} \mathrm{C} \text { to } 29.7646^{\circ} \mathrm{C}\end{array}$ & $\begin{array}{l}(\mathrm{Al}) ;(\mathrm{Zn}) ;(\mathrm{Sn}) ;(\mathrm{In}) \\
(\mathrm{Ga}) ;(\mathrm{Hg})\end{array}$ & $\begin{array}{l}\text { (Al-Zn); (Al-Sn); (Al-In); (Al-Ga); (Al-Hg); } \\
(\mathrm{Zn}-\mathrm{Sn}) ;(\mathrm{Zn}-\mathrm{In}) ;(\mathrm{Zn}-\mathrm{Ga}) ;(\mathrm{Zn}-\mathrm{Hg}) ;(\mathrm{Sn}-\mathrm{In}) ; \\
\text { (Sn-Ga); (Sn-Hg); (In-Ga); (In-Hg); (Ga-Hg) }\end{array}$ \\
\hline $\begin{array}{l}\text { Region } 2(\mathrm{R} 2) \text { : } \\
29.7646^{\circ} \mathrm{C} \text { to } 156.5985^{\circ} \mathrm{C}\end{array}$ & $(\mathrm{Al}) ;(\mathrm{Zn}) ;(\mathrm{Sn}) ;(\mathrm{In})$ & $\begin{array}{l}(\mathrm{Al}-\mathrm{Zn}) ;(\mathrm{Al}-\mathrm{Sn}) ;(\mathrm{Al}-\mathrm{In}) ;(\mathrm{Zn}-\mathrm{Sn}) ;(\mathrm{Zn}-\mathrm{In}) \\
(\mathrm{Sn}-\mathrm{In})\end{array}$ \\
\hline $\begin{array}{l}\text { Region } 3 \text { (R3): } \\
156.5985^{\circ} \mathrm{C} \text { to } 231.928^{\circ} \mathrm{C}\end{array}$ & $(\mathrm{Al}) ;(\mathrm{Zn}) ;(\mathrm{Sn})$ & $(\mathrm{Al}-\mathrm{Zn}) ;(\mathrm{Al}-\mathrm{Sn}) ;(\mathrm{Zn}-\mathrm{Sn})$ \\
\hline $\begin{array}{l}\text { Region } 4(\mathrm{R} 4) \text { : } \\
231.928^{\circ} \mathrm{C} \text { to } 419.527^{\circ} \mathrm{C}\end{array}$ & $(\mathrm{Al}) ;(\mathrm{Zn})$ & $(\mathrm{Al}-\mathrm{Zn})$ \\
\hline
\end{tabular}

will be designated in the suggestive manner used in the specific literature $[6,10,12]$ by means of the symbol of the metal whose fixed point temperature is the upper limit of the subrange. The exception is the subrange $-38.8344^{\circ} \mathrm{C}$ to $29.7646^{\circ} \mathrm{C}$, for which the symbol " $\mathrm{Hg}$ " is used. The subrange symbols will be written between brackets so they may not be mistaken for the symbols that designate fixed points. Also, a pair of subranges $(S j)$ and $\left(S_{h}\right)$ that overlap will be indicated very concisely by the symbol $\left(S_{j}-S_{h}\right)$.

The number of possible combinations of two subranges that overlap above $0{ }^{\circ} \mathrm{C}$ varies as follows (Table 2): (a) 15 , between $0{ }^{\circ} \mathrm{C}$ and $29.7646^{\circ} \mathrm{C}$ (Region 1); (b) 6, between $29.7646^{\circ} \mathrm{C}$ and $156.5985^{\circ} \mathrm{C}$ (Region 2); (c) 3, between $156.5985^{\circ} \mathrm{C}$ and $231.928^{\circ} \mathrm{C}$ (Region 3); (d) 1, between $231.928^{\circ} \mathrm{C}$ and $419.527^{\circ} \mathrm{C}$ (Region 4).

For any pair of overlapping subranges $\left(S_{j}\right)$ and $\left(S_{h}\right)$, the calculating the Simple Type 1 non-uniqueness can be done in two ways, starting from equation (2):

$1)$ at a given $W$ in the region of overlap: NU-1 is the difference between the reference functions $W_{r}^{\left(S_{j}\right)}$ and, respectively, $W_{r}^{\left(S_{h}\right)}$ determined at $W$ in accordance with the two definitions of the ITS-90:

$$
\begin{aligned}
(\mathrm{NU}-1)^{\left(S_{j}-S_{h}\right)}= & W_{r}^{\left(S_{j}\right)}-W_{r}^{\left(S_{h}\right)} \\
= & \left(W^{\left(S_{j}\right)}-\Delta W^{\left(S_{j}\right)}\right)-\left(W^{\left(S_{h}\right)}-\Delta W^{\left(S_{h}\right)}\right) \\
& =\Delta W^{\left(S_{h}\right)}-\Delta W^{\left(S_{j}\right)}
\end{aligned}
$$

where $W^{\left(S_{j}\right)}=W^{\left(S_{h}\right)}=W$.

2) at a given temperature $T_{90}$ in the region of overlap (meaning a given $W_{\mathrm{r}}$ ): NU-1 is the difference between the resistances ratios $W^{\left(S_{j}\right)}$ and, respectively, $W^{\left(S_{h}\right)}$ determined at $T_{90}$ in accordance with the two definitions of the ITS-90:

$$
\begin{aligned}
(\mathrm{NU}-1)^{\left(S_{j}-S_{h}\right)} & =W^{\left(S_{j}\right)}-W^{\left(S_{h}\right)} \\
& =\left(W_{\mathrm{r}}^{\left(S_{j}\right)}+\Delta W^{\left(S_{j}\right)}\right) \\
& -\left(W_{\mathrm{r}}^{\left(S_{h}\right)}+\Delta W^{\left(S_{h}\right)}\right) \\
& =\Delta W^{\left(S_{j}\right)}-\Delta W^{\left(S_{h}\right)},
\end{aligned}
$$

where $W_{r}^{\left(S_{j}\right)}=W_{r}^{\left(S_{h}\right)}=W_{r}$

Note: Hereafter we shall refer only to Case 1, because Case 2 can be easily derived from the first by changing the sign, see (3) and (4). 
It follows that Type 1 non-uniqueness for the $\left(S_{j}-S_{h}\right)$ pair can be expressed by the difference between the deviation functions $\Delta W^{\left(S_{j}\right)}$ and $\Delta W^{\left(S_{h}\right)}$ specific to the two overlapping subranges. But each deviation function $\Delta W$ can be expressed in terms of its values obtained directly from the calibration of the thermometer at the fixed points $(\mathrm{FP})$ in the respective subrange; these values are hereafter termed deviations and denoted by $\Delta W_{\mathrm{FP}}$. Thus, for the subrange $\left(S_{j}\right)$, the deviation function can be written in the form

$$
\begin{aligned}
\Delta W^{\left(S_{j}\right)} & =f_{\mathrm{FP} 1}^{\left(S_{j}\right)} \Delta W_{\mathrm{FP} 1}+f_{\mathrm{FP} 2}^{\left(S_{j}\right)} \Delta W_{\mathrm{FP} 2}+\ldots+f_{\mathrm{FP} N}^{\left(S_{j}\right)} \Delta W_{\mathrm{FP} N} \\
& =\sum_{i=1}^{N} f_{\mathrm{FP} i}^{\left(S_{j}\right)} \Delta W_{\mathrm{FP} i}
\end{aligned}
$$

where $f_{\mathrm{FP} i}^{\left(S_{j}\right)}$ are polynomial functions of $W$ and of the ratios of resistances $W_{\mathrm{FP} i}$ determined at the $N$ points of calibration in the respective subrange, except for the triple point of water $(N \leq 3)$.

The expressions of the functions $f_{\mathrm{FP} i}^{\left(S_{j}\right)}$ can be derived through elementary algebra: by solving a linear equation with one variable or by solving systems of linear equations with 2 or 3 variables. The functions $f_{\mathrm{FP} i}^{\left(S_{j}\right)}$ will be called hereafter functions of propagation, because, through them, the deviations $\Delta W_{\mathrm{FP} i}$ are propagated from the temperatures of fixed points to intermediary temperatures. The formulae ${ }^{1}$ of $f_{\mathrm{FP} i}^{\left(S_{j}\right)}$ are given in Appendix A, Section A.1.

For the sake of simplicity and concreteness, let us consider one of the subranges above $0^{\circ} \mathrm{C}$ of the ITS-90, say (Zn). After rearranging the expressions obtained for the coefficients $a$ and $b$ of the deviation function $\Delta W$ (Table 1$)$ in terms of the deviations $\Delta W_{\mathrm{Sn}}$ and $\Delta W_{\mathrm{Zn}}$, the interpolating equation becomes

$$
\Delta W^{(\mathrm{Zn})}=f_{\mathrm{Sn}}^{(\mathrm{Zn})} \Delta W_{\mathrm{Sn}}+f_{\mathrm{Zn}}^{(\mathrm{Zn})} \Delta W_{\mathrm{Zn}},
$$

where $f_{\mathrm{Sn}}^{(\mathrm{Zn})}$ and $f_{\mathrm{Zn}}^{(\mathrm{Zn})}$ are functions of propagation, and their expressions are given in Appendix A, Section A.1.

Similarly, for the subrange (Sn), the deviation function is

$$
\Delta W^{(\mathrm{Sn})}=f_{\mathrm{In}}^{(\mathrm{Sn})} \Delta W_{\mathrm{In}}+f_{\mathrm{Sn}}^{(\mathrm{Sn})} \Delta W_{\mathrm{Sn}},
$$

with $f_{\mathrm{In}}^{(\mathrm{Sn})}$ and $f_{\mathrm{Sn}}^{(\mathrm{Sn})}$ given in Appendix A, Section A.1.

\footnotetext{
${ }^{1}$ Note that the analytical expressions of the propagation functions $f_{\mathrm{FP} i}^{\left(S_{j}\right)}$, that relate the deviation functions to the deviations at fixed points (Eq. (5)), are identical to the expressions of the "sensitivity coefficients $f_{i}(W)$ " derived in [11], where they relate the reference functions $W_{r}$ to their values at fixed points (which, as a matter of fact, are constants). But each set of functions $f_{i}(W)$ in [11] contains, in addition, a function that corresponds to the triple point of water, noted as $f_{\mathrm{H} 2 \mathrm{O}}$, or, in other words, each interpolation equation in [11] contains a supplementary term that corresponds to the triple point of water. These elements are not necessary when we work with the deviation functions, as shown above.
}

Type 1 non-uniqueness between subranges (Zn) and $(\mathrm{Sn})$ is obtained from (3) in combination with (6) and (7)

$$
\begin{gathered}
(\mathrm{NU}-1)^{(\mathrm{Zn}-\mathrm{Sn})}=\Delta W^{(\mathrm{Sn})}-\Delta W^{(\mathrm{Zn})} \\
=\left(f_{\mathrm{In}}^{(\mathrm{Sn})} \Delta W_{\mathrm{In}}+f_{\mathrm{Sn}}^{(\mathrm{Sn})} \Delta W_{\mathrm{Sn}}\right)-\left(f_{\mathrm{Sn}}^{(\mathrm{Zn})} \Delta W_{\mathrm{Sn}}+f_{\mathrm{Zn}}^{(\mathrm{Zn})} \Delta W_{\mathrm{Zn}}\right) \\
=g_{\mathrm{Sn}}^{(\mathrm{Zn}-\mathrm{Sn})} \Delta W_{\mathrm{Sn}}+g_{\mathrm{In}}^{(\mathrm{Zn}-\mathrm{Sn})} \Delta W_{\mathrm{In}}+g_{\mathrm{Zn}}^{(\mathrm{Zn}-\mathrm{Sn})} \Delta W_{\mathrm{Zn}}
\end{gathered}
$$

where $\quad g_{\mathrm{Sn}}^{(\mathrm{Zn}-\mathrm{Sn})}=f_{\mathrm{Sn}}^{(\mathrm{Sn})}-f_{\mathrm{Sn}}^{(\mathrm{Zn})}, \quad g_{\mathrm{Zn}}^{(\mathrm{Zn}-\mathrm{Sn})}=-f_{\mathrm{Zn}}^{(\mathrm{Zn})}, \quad$ and $g_{\text {In }}^{(\mathrm{Zn}-\mathrm{Sn})}=f_{\mathrm{In}}^{(\mathrm{Sn})}$.

Coming back to the general case now, the Simple Type 1 non-uniqueness between any 2 subranges $\left(S_{j}\right)$ and $\left(S_{h}\right)$ follows from (3) and (5)

$$
\begin{aligned}
(\mathrm{NU}-1)^{\left(S_{j}-S_{h}\right)} & =\Delta W^{\left(S_{h}\right)}-\Delta W^{\left(S_{j}\right)} \\
& =\sum_{l=1}^{M} f_{\mathrm{FP} l}^{\left(S_{h}\right)} \Delta W_{\mathrm{FP} l}-\sum_{i=1}^{N} f_{\mathrm{FP} i}^{\left(S_{j}\right)} \Delta W_{\mathrm{FP} i},
\end{aligned}
$$

where $M$ and $N$ represent the number of calibration points in subrange $\left(S_{h}\right)$ and, respectively, in subrange $\left(S_{j}\right)$ (except for the triple point of water). If there are fixed points common to both subranges that overlap (such as the freezing point of $\mathrm{Sn}$ in the example ( $\mathrm{Zn}-\mathrm{Sn}$ ) above), then the similar terms in the corresponding deviations are combined into one single term and (9) becomes

$$
(\mathrm{NU}-1)^{\left(S_{j}-S_{h}\right)}=\sum_{k=1}^{P} g_{\mathrm{FP} k}^{\left(S_{j}-S_{h}\right)} \Delta W_{\mathrm{FP} k} .
$$

$P$ is the sum of the calibration points $M$ and $N$, where the fixed points common to $\left(S_{j}\right)$ and $\left(\mathrm{S}_{h}\right)$ are included once.

Equation (10) represents the mathematical model of the Simple Type 1 non-uniqueness. It describes the relation between the output quantity - the Simple Type 1 nonuniqueness - and the input quantities - the functions $g_{\mathrm{FP} k}^{\left(S_{j}-S_{h}\right)}$ and the deviations $\Delta W_{\mathrm{FP} k}$. The expressions of the Simple Type 1 non-uniqueness for the 15 pairs of subranges that overlap above $0^{\circ} \mathrm{C}$ are presented in Appendix A, Section A. $2^{2}$.

$g_{\mathrm{FP} k}^{\left(S_{j}-S_{h}\right)}$ are polynomial functions of $W$ and of the ratios of resistances $W_{\mathrm{FP} i}$ at all the $P$ points of calibration in the subranges $S_{j}$ and $S_{h}$. It is important to note that the functions $g_{\mathrm{FP} k}^{\left(S_{j}-S_{h}\right)}$ are either identical to the propagation functions $f_{\mathrm{FP} i}^{\left(S_{j}\right)}$ and $f_{\mathrm{FP} i}^{\left(S_{h}\right)}$, or they are algebraic sums of the latter (Appendix A, Section A.2). For the sake of simplicity, the functions $g_{\mathrm{FP} k}^{\left(S_{j}-S_{h}\right)}$ shall be named hereafter combined functions of propagation or, shortly, functions of propagation.

If we substitute $W_{\mathrm{FP} k}=W_{\mathrm{r}, \mathrm{FP} k}$, where $W_{\mathrm{r}, \mathrm{FP} k}$ are constants - substitution that generates negligible errors in NU-1 (less than $1 \mu \mathrm{K})-$, then each function $g_{\mathrm{FP} k}^{\left(S_{j}-S_{h}\right)}$ in (10) becomes a function of a single variable, namely of $W$.

\footnotetext{
$\overline{{ }^{2}}$ One of the equations - namely, the equation of $(\mathrm{NU}-1)^{(\mathrm{Al}-\mathrm{Zn})}-$ is identical to the formula derived in [9] by factoring and Lagrange interpolation that we have mentioned in Introduction.
} 
As a result, at a $W$ given, $g_{\mathrm{FP} k}^{\left(S_{j}-S_{h}\right)}$ becomes constant and the only variables remaining in the expression (10) are the deviations $\Delta W_{\mathrm{FP} k}$. So, the proposed model (10) provides an extremely simple and rapid manner to calculate the values of the Simple Type 1 non-uniqueness.

Yet, in its exact meaning, the Type 1 non-uniqueness at a given $W$ is to be considered in reference to all subranges that include this $W$ value, not only to two of them. The number of subranges that overlap differs from one region to another (Table 2): (a) six, in Region 1; (b) four, in Region 2; (c) three, in Region 3; (d) two, in Region 4.

\subsection{The Combined Type 1 non-uniqueness}

The text of the ITS-90 [1] states the Type 1 non-uniqueness of the Scale:

For measurements of the very highest precision there may be detectable numerical differences between measurements made at the same temperature but in accordance with differing definitions.

But which of the different values determined "at the same temperature" is closer to the value of the measurand ${ }^{3}$ ? Is it the one obtained through the calibration in the subrange $(\mathrm{Al})$ or the one obtained through the calibration in the subrange $(\mathrm{Zn}),(\mathrm{Sn}),(\mathrm{In}),(\mathrm{Ga})$ or $(\mathrm{Hg})$ - if we refer, for instance, to Region 1 (Table 2)? Obviously, we can not know. What we do know for sure is that the 6 values may be affected by the non-uniqueness of the Scale and that they should then be corrected.

Under the current approach, the values of NU-1 are calculated as the differences between two subranges that overlap. But the values of the Type 1 non-uniqueness thus calculated at a given $W$ (or a given $T_{90}$ ) for the different combinations of two subranges may also significantly differ from one another. If, for instance, the calibration has been made in the subrange $(\mathrm{Al})$, then which is the value of NU-1 at $W$ : the difference calculated for the pair $(\mathrm{Al}-\mathrm{Zn})$ or for the pair (Al-Sn), (Al-In), (Al-Ga) or (Al-Hg)? We can not know that either. For this reason, we have proposed a new approach where NU-1 at $W$ is evaluated between all subranges that contain the respective $W$, not only for combinations of two.

Specifically, the Type 1 non-uniqueness at a given $W$ between more than two overlapping subranges, hereafter called Combined Type 1 non-uniqueness, can be calculated in two ways:

1) as the difference between the value of the reference function $W_{\mathrm{r}}$ determined at $W$ in calibration subrange and the arithmetic mean of the values of $W_{\mathrm{r}}$ determined at the same $W$ in the other subranges that it overlaps.

For example, if the calibration was performed in the subrange $0^{\circ} \mathrm{C}$ to $660.323^{\circ} \mathrm{C}$, then, in one of the regions of overlap, say Region 1 (R1), the Combined Type 1 non-

\footnotetext{
${ }^{3}$ The measurand is the resistances ratio $W$ of a given SPRT at a specified temperature between the defining fixed points. It should not be confused with the realised quantities using the values assigned to the fixed points and the equations of the ITS-90: these are only approximations of the measurand due to incomplete knowledge of certain physical phenomena [24].
}

uniqueness between subrange $(\mathrm{Al})$ and the other 5 subranges that it overlaps shall be given by:

$$
\begin{aligned}
& (\mathrm{NU}-1)^{(\mathrm{Al}), \mathrm{R} 1} \\
& =W_{\mathrm{r}}^{(\mathrm{Al})}-\frac{W_{\mathrm{r}}^{(\mathrm{Zn})}+W_{\mathrm{r}}^{(\mathrm{Sn})}+W_{\mathrm{r}}^{(\mathrm{In})}+W_{\mathrm{r}}^{(\mathrm{Ga})}+W_{\mathrm{r}}^{(\mathrm{Hg})}}{5},
\end{aligned}
$$

where the superscript "R1" is used to indicate the region of overlap under analysis.

2) as the arithmetic mean of the Simple Type 1 nonuniqueness values for the pairs of overlapping subranges, that, for the example above, are (Al-Zn), (Al$\mathrm{Sn}),(\mathrm{Al}-\mathrm{In}),(\mathrm{Al}-\mathrm{Ga})$ and $(\mathrm{Al}-\mathrm{Hg})$ :

$$
\begin{aligned}
(\mathrm{NU}- & 1)^{(\mathrm{Al}), \mathrm{R} 1}=\frac{\left(W_{\mathrm{r}}^{(\mathrm{Al})}-W_{\mathrm{r}}^{(\mathrm{Zn})}\right)+\left(W_{\mathrm{r}}^{\mathrm{Al}}-W_{\mathrm{r}}^{(\mathrm{Sn})}\right)}{5} \\
& +\frac{\left(W_{\mathrm{r}}^{(\mathrm{Al})}-W_{\mathrm{r}}^{(\mathrm{In})}\right)+\left(W_{\mathrm{r}}^{(\mathrm{Al})}-W_{\mathrm{r}}^{(\mathrm{Ga})}\right)+\left(W_{\mathrm{r}}^{(\mathrm{Al})}-W_{\mathrm{r}}^{(\mathrm{Hg})}\right)}{5} \\
& =W_{\mathrm{r}}^{(\mathrm{Al})}-\frac{W_{\mathrm{r}}^{(\mathrm{Zn})}+W_{\mathrm{r}}^{(\mathrm{Sn})}+W_{\mathrm{r}}^{(\mathrm{In})}+W_{\mathrm{r}}^{(\mathrm{Ga})}+W_{\mathrm{r}}^{(\mathrm{Hg})}}{5}
\end{aligned}
$$

Equation (12) is identical to equation (11) and it represents the mathematical model of the Combined Type 1 non-uniqueness between the subrange $(\mathrm{Al})$ and the other 5 that it overlaps in Region 1.

Similar equations can also be written for the other regions of overlap and calibration subranges. The equations can be expressed explicitly in terms of the propagation functions and the deviations $\Delta W_{\mathrm{FP}}$, using only a few elementary algebra operations. But these formulas are of limited interest for the subject of our article. The correction applied to the interpolated value in order to compensate for the effect of the Type 1 non-uniqueness of the Scale can take neither the form of Simple Type 1 non-uniqueness (10), nor the form of Combined Type 1 non-uniqueness (11) or (12). Instead, the new concept of Correction for the Type 1 non-uniqueness of the Scale will be introduced, which plays an important role in the proposed approach.

\section{The correction for the Type 1 non- uniqueness of the Scale and its standard uncertainty}

For any pair of overlapping subranges, $\left(\mathrm{S}_{j}\right)$ and $\left(S_{h}\right)$, the mathematical model of the Simple Type 1 non-uniqueness is given by (10). Therefore, the (combined) standard uncertainty of the Simple Type 1 non-uniqueness between $\left(\mathrm{S}_{j}\right)$ and $\left(S_{h}\right)$ subranges, denoted by $u_{\mathrm{NU}-1}^{\left(S_{j}-S_{h}\right)}$, is obtained by combining the standard uncertainties associated with the deviations $\Delta W_{\mathrm{FP} k}$, which are the only input quantities in the model (10). But $\Delta W_{\mathrm{FP} k}=W_{\mathrm{FP} k}-W_{\mathrm{r}, \mathrm{FP} k}$, where $W_{\mathrm{r}, \mathrm{FP} k}$ are constants, so that, in fact, $u_{\mathrm{NU}-1}^{\left(S_{j}-S_{h}\right)}$ is obtained by combining the standard uncertainties associated with the resistances ratios determined at the fixed points, $u\left(W_{\mathrm{FP} k}\right)$. The subject is developed in [16], but the authors neglect the correlations among the input quantities because of the complexity of the expression for the combined standard 
uncertainty. There is a simple way to eliminate the necessity to evaluate the covariance when calculating $u_{\mathrm{NU}-1}^{\left(S_{j}-S_{h}\right)}$. It consists [20-22] of the expression of the resistances $R_{\mathrm{FP}}$ and $R_{\mathrm{TPW}}$ of the ratio $W_{\mathrm{FP}}=R_{\mathrm{FP}} / R_{\mathrm{TPW}}$ in terms of independent input quantities, based on the physical phenomena involved in the measurement process. Furthermore, a direct link between the accuracy of measurement and the manageable physical factors involved can thus be traced. Also, an analysis of different cases of correlation and a study on their influence on the combined standard uncertainty are presented in [23].

Here, we shall not develop the evaluation method for the standard uncertainty of the Simple Type 1 nonuniqueness $u_{\mathrm{NU}-1}^{\left(S_{j}-S_{h}\right)}$ because it can not be a component of uncertainty in realising the ITS-90. For two reasons.

1) The first reason is as simple and obvious as possible. In order to evaluate $u_{\mathrm{NU}-1}^{\left(S_{j}-S_{h}\right)}$, we need to know, according to (10), the uncertainties $u\left(W_{\mathrm{FP} k}\right)$ both at the fixed points in the subrange where calibration was performed, let us say subrange $\left(S_{j}\right)$, and at the fixed points in the other subrange, $\left(S_{h}\right)$. In most cases, the data for $\left(S_{h}\right)$ do not exist and, then, the calculation of $u_{\mathrm{NU}-1}^{\left(S_{j}-S_{h}\right)}$ is impossible. The situation is the more so complicated in the regions where more subranges overlap.

Under these conditions, the uncertainty in knowing the Type 1 non-uniqueness of the Scale is evaluated based on observations made outside the current calibration, and this component of uncertainty in realising the ITS-90 will be treated just like the components that are directly determined in the current calibration.

The evaluation method of the uncertainty associated with the effect of the Type 1 non-uniqueness of the Scale is based on statistical analysis of data derived from a large number of calibrations made at the fixed points, in several primary thermometry laboratories and using a set of very stable SPRTs. The aim of the study is to determine, from a finite sample of data, the best estimates of parameters that describe the (infinite) population of all such possible measurements. These parameters are: the mean of the population (or expectation), $\mu$, i.e. the value of the measurand, and the standard deviation, $\sigma$, that characterise the dispersion of the theoretically infinite number of measured values of the measurand about $\mu$. The best estimate of $\mu$ is the average (or the arithmetic mean) of the sample, $M$, and the best estimate of $\sigma$ is the standard deviation of the sample, called experimental standard deviation [24] and hereafter denoted by ESD or $s$. An additional measurement (one different from those in the sample) will fall within the individual members of the entire population. Since the sample mean $M$ and the experimental standard deviation $s$ are unbiased estimates of $\mu$ and $\sigma$, an additional measurement will fall within $M \pm 2 s$ at a level of confidence of approximately 95 percent for a normal distribution.

Sets of data obtained from the calibration of a large group of SPRTs above $0{ }^{\circ} \mathrm{C}$ were already used in $[9,10,12,13]$, but the characteristics under study were
Simple Type 1 non-uniqueness and its uncertainty. This article proposes a substantive departure from the traditional method, and the new approach is presented

2) Helow. included as a component of the uncertainty in realising the ITS-90 because Type 1 non-uniqueness, as it is defined [1,2,3], is not an input quantity for the mathematical models of interpolations made between fixed points. This statement is substantiated in the next section.

Now, let us just take a moment to point out that any uncertainty evaluation process should be preceded by the elaboration of the measurement model: the development of reliable models prevents faulty evaluation of the uncertainty. Unfortunately, few studies are available that observe this imperative.

Before proceeding to the presentation of the proposed approach, we will briefly discuss the current approach.

\subsection{The current approach}

Let us analyse the case of uncertainty associated with $T_{90}$ at a given $W$ in the region of overlap of a subranges pair when a calibration according to the ITS-90 is performed. The case has been dealt with in [11], where the combined variance of $T_{90}$ is described in the equation (9.8)

$$
u_{\text {total }}^{2}(T)=\left(\frac{d T}{d W}\right)^{2}\left[u^{2}\left(W_{\mathrm{r}}\right)+u^{2}\left(\Delta W_{\mathrm{SRI}}\right)+u^{2}\left(\Delta W_{\mathrm{NU}}\right)\right]
$$

by the sum of the variance in "the interpolated resistance ratio", $u^{2}\left(W_{\mathrm{r}}\right)$ and the variance "due to Type 1 nonuniqueness (subrange inconsistency)", $u^{2}\left(\Delta W_{\mathrm{SRI}}\right)$ [11]. (An identical treatment of the case is given in [3, Chapter 5].) The variance "due to Type 3 non-uniqueness" $u^{2}\left(\Delta W_{\mathrm{NU}}\right)$ is not the subject of this article and we shall ignore it. $u\left(\Delta W_{\mathrm{SRI}}\right)$ is characterised $[11,10,3]$ by standard deviation of differences between two subranges that overlap.

No mathematical model is in place for equation (9.8) in [11]; but since only two input quantities, uncorrelated, are involved, and the sensitivity coefficients are equal to 1 , we can develop the model here without any difficulty.

The Type 1 non-uniqueness is considered in $[11,3]$ to be dominated by the difference between the $(\mathrm{Al})$ and $(\mathrm{Zn})$ subranges over most of the $0^{\circ} \mathrm{C}$ to $420^{\circ} \mathrm{C}$ subrange. Let us suppose that the calibration of the SPRT was performed in the subrange $(\mathrm{Al})$. If we slightly modify the notation used in [11] in order to preserve the homogeneity of our article, the mathematical model corresponding to (9.8) in [11] is simply

$$
W_{\mathrm{r}, \text { corrected }}=W_{r}^{(\mathrm{Al})}+\Delta W_{\mathrm{r}, \mathrm{NU}-1}
$$

where $W_{r}^{(\mathrm{Al})}$ is the value interpolated in the calibration subrange $(\mathrm{Al})$ and $\Delta W_{\mathrm{r}, \mathrm{NU}-1} \equiv \Delta W_{\mathrm{SRI}}$ is the correction applied to compensate for Simple Type 1 non-uniqueness (or subrange inconsistency) between $(\mathrm{Al})$ and $(\mathrm{Zn})$ subranges. For $\Delta W_{\mathrm{r}, \mathrm{NU}-1}$, we use the model 


$$
\Delta W_{\mathrm{r}, \mathrm{NU}-1}=W_{\mathrm{r}}^{(\mathrm{Zn})}-W_{\mathrm{r}}^{(\mathrm{Al})},
$$

where $W_{\mathrm{r}}^{(\mathrm{Al})}$ and $W_{\mathrm{r}}^{(\mathrm{Zn})}$ are the values determined according to the two different definitions of the ITS-90.

Then (13) becomes

$$
W_{\mathrm{r}, \text { corrected }}=W_{\mathrm{r}}^{(\mathrm{Al})}+\left(W_{\mathrm{r}}^{(\mathrm{Zn})}-W_{\mathrm{r}}^{(\mathrm{Al})}\right)=W_{\mathrm{r}}^{(\mathrm{Zn})} .
$$

It follows that, once we apply the correction $\Delta W_{\mathrm{r}, \mathrm{NU}-1}$ (i.e. $\left.\Delta W_{\mathrm{SRI}}\right), W_{\mathrm{r}}^{(\mathrm{Al})}$ is simply replaced with $W_{\mathrm{r}}^{(\mathrm{Zn})}$, or, in other words, one definition of $T_{90}$ is replaced by another. Nothing makes $W_{\mathrm{r}}^{(\mathrm{Zn})}$ "truer" than $W_{\mathrm{r}}^{(\mathrm{Al})}$, they have equal status. Therefore, the use of correction $\Delta W_{\mathrm{r}, \mathrm{NU}-1} \equiv \Delta W_{\mathrm{SRI}}$ is intrinsically unsuited for mathematical modelling of $T_{90}$ (or $W_{\mathrm{r}}$ ).

\subsection{The new approach}

One of the basic differences from the conventional approach lies in the consideration that the effect generated by the Type 1 non-uniqueness of the Scale on the interpolated value is not equal to the difference between $W_{\mathrm{r}}^{(\mathrm{Al})}$ and $W_{\mathrm{r}}^{(\mathrm{Zn})}$, but to the difference between the $W_{\mathrm{r}}$ value determined in the calibration subrange and the arithmetic mean ${ }^{4}$ of the $W_{\mathrm{r}}$ values determined in all subranges that overlap.

The corrected result of the interpolation is not the value of the reference function $W_{\mathrm{r}}$ determined in one subrange or another, but it should be the best estimate available of the value of $W \mathrm{r}$ whatever the subrange in which measurements were made. We therefore introduce the new concept of Correction for the Type 1 non-uniqueness of the Scale, $C_{\mathrm{NU}-1}$. The proposed mathematical model for this correction allows one to calculate the uncertainty in knowing the Type 1 non-uniqueness of the Scale at a given $W$ separately for each calibration subrange that contain the respective $W$. Just as the corrections for the recognized systematic effects (the self heating effect, the hydrostatic head of liquid in the cell, the deviation of the pressure of gas in the fixed point cell from the Reference pressure, etc.) are included in the mathematical model of the measurement at the fixed points, $C_{\mathrm{NU}-1}$ will be included in the mathematical model of interpolation.

Let us consider the region between $232^{\circ} \mathrm{C}$ and $420^{\circ} \mathrm{C}$ where only the $(\mathrm{Al})$ and $(\mathrm{Zn})$ subranges overlap. Assuming again that the calibration of SPRT has been performed in the subrange $(\mathrm{Al})$, the correction $C_{\mathrm{NU}-1}^{(\mathrm{Al})}$ in the Region 4 (Table 2) is defined by:

$$
C_{\mathrm{NU}-1}^{(\mathrm{Al})}=\bar{W}_{\mathrm{r}}-W_{\mathrm{r}}^{(\mathrm{Al})}
$$

where $\bar{W}_{\mathrm{r}}$ is the arithmetic mean $\bar{W}_{\mathrm{r}}=\frac{W_{\mathrm{r}}^{(\mathrm{Al})}+W_{\mathrm{r}}^{(\mathrm{Zn})}}{2}$. The mathematical model of the interpolation then becomes

$$
\begin{aligned}
W_{\mathrm{r}, \text { corrected }} & =W_{\mathrm{r}}^{(\mathrm{Al})}+C_{\mathrm{NU}-1}^{(\mathrm{Al})} \\
& =W_{\mathrm{r}}^{(\mathrm{Al})}+\left(\bar{W}_{\mathrm{r}}-W_{\mathrm{r}}^{(\mathrm{Al})}\right)=\bar{W}_{\mathrm{r}} .
\end{aligned}
$$

\footnotetext{
$\overline{4}$ The arithmetic mean uses all the values of a given set and can be seen as their "balance point".
}

The corrected result at a given $W$ in the region of overlap of the subranges $(\mathrm{Al})$ and $(\mathrm{Zn})$ is equal to the arithmetic mean $\bar{W}_{\mathrm{r}}$ of the values of $W_{\mathrm{r}}$ determined at $W$ in the two subranges.

The same procedure is applicable in the case of more than two subranges that overlap. For example, in the case of a temperature region where $J$ subranges overlap and the thermometer is calibrated in the subrange $(\mathrm{Al})$, the correction $C_{\mathrm{NU}-1}^{(\mathrm{Al})}$ is also expressed by $(16)$, but where $\bar{W}_{\mathrm{r}}$ is the arithmetic mean of the values of $W_{\mathrm{r}}$ determined in all of the $J$ subranges:

$$
\bar{W}_{\mathrm{r}}=\frac{1}{J} \sum_{j=1}^{J} W_{\mathrm{r}}^{(S j)} .
$$

Also in this case, the mathematical model of the interpolation is given by (17), where $\bar{W}_{\mathrm{r}}$ is defined by (18). Similar expressions are obtained in case the thermometer is calibrated in the subrange $(\mathrm{Zn}),(\mathrm{Sn})$, (In), (Ga) or $(\mathrm{Hg})$.

The corrections $C_{\mathrm{NU}-1}$ can be expressed, in their turn, in terms of the deviations $\Delta W_{\mathrm{FP}}$ and in terms of the propagation functions; their analytical expressions are presented in Appendix A, Section A.3, for each region of overlap and each calibration subrange.

If a thermometer is not calibrated at all the fixed points in the overlapping subranges, the results are not sufficient for the calculation of $C_{\mathrm{NU}-1}$ in (16) and its uncertainty. In this case, $C_{\mathrm{NU}-1}$ could be estimated by the statistical analysis of the data derived from a large number $K$ of calibrations made at all the fixed points involved, in several primary thermometry laboratories and using a large set of very stable SPRTs.

The estimate of $C_{\mathrm{NU}-1}$ for a calibration subrange, say $\left(S_{j}\right)$, can be then taken as the arithmetic mean of the $C_{\mathrm{NU}-1, k}^{\left(S_{j}\right)}$ values, $k=1, \ldots, K$, derived from the results of the $K$ calibrations. Thus, the estimate of the input quantity $C_{\mathrm{NU}-1}$ will not be derived directly from the current calibration, but will be brought into the interpolation model (17) from external sources [24,25]. The arithmetic mean, $M_{\mathrm{NU}-1}^{\left(S_{j}\right)}$, is obtained from

$$
M_{\mathrm{NU}-1}^{\left(S_{j}\right)}=\frac{1}{K} \sum_{k=1}^{K} C_{\mathrm{NU}-1, k}^{\left(S_{j}\right)}=\frac{1}{K} \sum_{k=1}^{K}\left(\bar{W}_{\mathrm{r}, k}-W_{\mathrm{r}, k}^{\left(S_{j}\right)}\right),
$$

where $C_{\mathrm{NU}-1, k}^{\left(S_{j}\right)}, \bar{W}_{\mathrm{r}, k}$ and $W_{\mathrm{r}, k}^{\left(S_{j}\right)}$ are the values derived from the results of the $k$ th calibration.

But determining the estimate of $C_{\mathrm{NU}-1}^{\left(S_{j}\right)}$ is only one stage of the process of evaluating this input quantity in the model (17). The second step involves the assessment of its associated uncertainty, $u\left(C_{\mathrm{NU}-1}^{\left(S_{j}\right)}\right)$. It is characterized by the standard deviation of the observations, $s\left(C_{\mathrm{NU}-1}^{\left(S_{j}\right)}\right)$, which is obtained from

$$
\begin{aligned}
s^{2}\left(C_{\mathrm{NU}-1}^{\left(S_{j}\right)}\right) & =\frac{1}{K-1} \sum_{k=1}^{K}\left[C_{\mathrm{NU}-1, k}^{\left(S_{j}\right)}-M_{\mathrm{NU}-1}^{\left(S_{j}\right)}\right]^{2} \\
& =\frac{1}{K-1} \sum_{k=1}^{K}\left[\left(\bar{W}_{\mathrm{r}, k}-W_{\mathrm{r}, k}^{\left(S_{j}\right)}\right)-M_{\mathrm{NU}-1}^{\left(S_{j}\right)}\right]^{2}
\end{aligned}
$$


A somewhat similar approach concerning the evaluation of the standard uncertainty of the Type 1 non-uniqueness has been developed in [16] but, in their formulas, the authors ignore the average calculated for the entire set of values under analysis (denoted by $M_{\mathrm{NU}-1}^{\left(S_{j}\right)}$ in our study).

\section{Data analysis}

The data for this study were derived from the results of a key comparison, namely CCT-K3 [19], in which each thermometer was calibrated in two or more laboratories. The main advantages derived from the use of the CCT-K3 results are:

(1) The calculation of the correction $C_{\mathrm{NU}-1}$ at temperatures above $0{ }^{\circ} \mathrm{C}$ requires the knowledge of the values of $\Delta W_{\mathrm{FP}}$ at all of the fixed points in overlapping subranges. The calibrations are usually carried out on a single subrange above $0^{\circ} \mathrm{C}$, while the calibrations performed in the inter-laboratory comparisons cover the fixed points in several subranges; and, in all of these comparisons, CCT-K3 is the only one that covers, in addition to the triple point of water, all of the six fixed points of interest for the subject of this article: the triple point of mercury, the melting point of gallium, and the freezing points of indium, tin, zinc and aluminium.

(2) If the measurements are performed in a single laboratory, then the unrecognized systematic effects and the partially reduced (recognized) systematic effects are inherently present in all the results obtained in that laboratory at a fixed point and, thus, in the mean calculated for the data sample. By contrast, it is possible that some local effects affecting the results of measurements made in different laboratories can compensate for each other to some extent in the arithmetic mean of the sample. Moreover, in case of comparisons, the presence of significant local effects becomes immediately obvious by comparing the results obtained with the same SPRT in different laboratories.

(3) In general, the measurements made by the primary laboratories participating in the comparison are of the highest accuracy.

We shall not rewrite here the results of CCT-K3, which are presented in an extremely rigorous manner in [19]. We shall only remind certain general information regarding the organisation of the comparison that is relevant for this study:

- The comparison involved measurements in 15 primary thermometry laboratories and the $W_{\mathrm{FP}}$ values at the fixed points were determined;

- Only part of the participating laboratories made measurements at all of the fixed points covered by comparison;

- 7 SPRTs were used from 3 different commercial sources: 4 Model M1, 2 Model M2 and 1 Model M3;

- Each participating laboratory calibrated one up to three SPRTs, and the coordinating laboratory - six SPRTs.

\subsection{The case of the correction $\mathrm{C}_{\mathrm{NU}-1}$}

We shall consider a complete set of results to be the group of values of the resistances ratio $W_{\mathrm{FP}}$ determined at all of the six fixed points by a participating laboratory using a SPRT. Given the definition of $C_{\mathrm{NU}-1}$, only one complete set of results per laboratory per thermometer in [19] has been taken into account in the process of forming the sample on which our study is based.

In the process of data analysis for the variable $C_{\mathrm{NU}-1}$, we first investigated whether the data contain values that are extremely different from the others - the so-called outliers. Identification of the extreme values in the tails of the distribution and decision to either keep or discard them are two essential parts of the statistical analysis. The presence of a single outlier can severely distort the values of certain statistics indispensable for our analysis, such as the mean or the standard deviation.

First, we used the Tukey's box-plot method [26] of inner and outer "fences", a hybrid method to identify the outliers. 5 outside [26] values - values between the inner and the outer fences - and 7 far out [26] values - extreme values beyond the outer fences - were identified. 5 of the 7 probable outliers represent the same laboratory and the same SPRT, but 5 different subranges; similarly, 2 of the 5 possible outliers represent another laboratory and SPRT and 2 different subranges.

Since the presence of the outliers influences the normality of the distribution, before applying the outlier detection test, we performed the normality evaluation using the ShapiroWilk test [27]. The test results showed, for a significance level of 0.05 , a non-normal distribution ( $\mathrm{p}$-values $<0.05$ in the majority of the regions of overlap). We assumed that the distribution is disturbed by the presence of outliers and that it will regain normality after their elimination.

The outlier identification was then performed using Grubbs' model-based test [28], for a significance level of 0.05. 7 outliers were detected that belong to the 12 revealed through Tukey's method.

There is no unanimous opinion of experts on what to do with the detected outliers. In this study, the decision process was facilitated by the possibility ensured by CCTK3 to compare each outlying value against the other values in the loop to which it belongs, all of them being determined with one and the same SPRT. Moreover, we evaluated the influence of the outliers on sample standard deviation by calculating its value with and without outliers; for each subrange, the maximum value decreased by more than $25 \%$ after the elimination of outliers.

The final decision was to eliminate the 7 outliers - in fact, the values of $C_{\mathrm{NU}-1}^{(\mathrm{Al})}, C_{\mathrm{NU}-1}^{(\mathrm{Zn})}, C_{\mathrm{NU} 1}^{(\mathrm{Sn})}, C_{\mathrm{NU}-1}^{(\mathrm{In})}$, and $C_{\mathrm{NU}-1}^{(\mathrm{Hg})}$ calculated from the measurement results of a participating laboratory and the values of $C_{\mathrm{NU}-1}^{(\mathrm{Ga})}$ and $C_{\mathrm{NU}-1}^{(\mathrm{Hg})}$ calculated from the measurement results of another participating laboratory. The extreme values of the remaining sample were checked again using the same Grubbs' test, but no outlier has been detected.

We reinvestigated then the normality of the distributions, for a significance level of 0.05, using Shapiro-Wilk test. With the exception of the distribution of the variable $C_{\mathrm{NU}-1}^{\mathrm{Sn})}$ in Region 1 (where $0.02 \leq \mathrm{p}$-values $\leq 0.05$ ) and of the distribution of the variable $C_{\mathrm{NU}-1}^{(\mathrm{Hg})}$ between $15^{\circ} \mathrm{C}$ and $25^{\circ} \mathrm{C}$ (where $0.03 \leq \mathrm{p}$-values $\leq 0.05$ ), all of the other distributions passed the test of normality this time. (The remaining $C_{\mathrm{NU}-1}^{(S j)}$ values are graphically represented as a function of temperature in Appendix B, Figure B.1.) 
Table 3. Descriptive statistics for $\mathrm{C}_{\mathrm{NU}-1}$.

\begin{tabular}{lllllll}
\hline $\begin{array}{l}\text { Calibration subrange } \\
S_{j}\end{array}$ & Sample size, $n$ & $\begin{array}{l}\text { Maximum } \\
\text { of } \\
M_{\mathrm{NU}-1}^{\left(S_{j}\right)} / \mathrm{mK}\end{array}$ & $\begin{array}{l}\text { Minimum } \\
\text { of } \\
M_{\mathrm{NU}-1}^{\left(S_{j}\right)} / \mathrm{mK}\end{array}$ & $\begin{array}{l}\text { Maximum } \\
\text { of } \\
s\left(C_{\mathrm{NU}-1}^{(S j)}\right) / \mathrm{mK}\end{array}$ & $\begin{array}{l}\text { Maximum } \\
\text { of } \\
C_{\mathrm{NU}-1} / \mathrm{mK}\end{array}$ & $\begin{array}{l}\text { Minimum } \\
\text { of } \\
C_{\mathrm{NU}-1} / \mathrm{mK}\end{array}$ \\
\hline$(\mathrm{Al})$ & 17 & 0.148 & -0.001 & 0.258 & 0.735 & -0.266 \\
$(\mathrm{Zn})$ & 17 & 0.196 & -0.017 & 0.189 & 0.484 & -0.157 \\
$(\mathrm{Sn})$ & 17 & 0.000 & -0.195 & 0.251 & 0.186 & -0.700 \\
$(\mathrm{In})$ & 17 & 0.000 & -0.185 & 0.187 & 0.096 & -0.560 \\
$(\mathrm{Ga})$ & 17 & 0.033 & -0.004 & 0.072 & 0.190 & -0.093 \\
$(\mathrm{Hg})$ & 16 & 0.093 & 0.000 & 0.066 & 0.201 & -0.032 \\
\hline
\end{tabular}

Table 4. Coefficients of equation (21) for each region of overlap.

\begin{tabular}{|c|c|c|c|c|c|}
\hline Subrange $S_{j}$ & $\mathrm{a}_{i} / \mathrm{mK}$ & $\begin{array}{c}\text { Region 1: } \\
0^{\circ} \mathrm{C} \text { to } \\
29.7646^{\circ} \mathrm{C} \\
\end{array}$ & $\begin{array}{c}\text { Region 2: } \\
29.7646^{\circ} \mathrm{C} \text { to } \\
156.5985^{\circ} \mathrm{C} \\
\end{array}$ & $\begin{array}{c}\text { Region } 3: \\
156.5985^{\circ} \mathrm{C} \text { to } \\
231.928^{\circ} \mathrm{C}\end{array}$ & $\begin{array}{c}\text { Region } 4 \text { : } \\
231.928^{\circ} \mathrm{C} \text { to } \\
419.527^{\circ} \mathrm{C} \\
\end{array}$ \\
\hline \multirow[t]{4}{*}{$\overline{(\mathrm{Al})}$} & $a_{0}$ & 3.42632 & -0.87770 & -1.29270 & 0.67155 \\
\hline & $a_{1}$ & -6.75875 & 0.93817 & 1.81641 & -1.22769 \\
\hline & $a_{2}$ & 3.33246 & 0.15951 & -0.59880 & 0.69910 \\
\hline & $a_{3}$ & 0 & -0.21989 & 0 & -0.12572 \\
\hline \multirow[t]{4}{*}{ (Zn) } & $a_{0}$ & 2.71847 & -1.93022 & -1.22718 & -0.67155 \\
\hline & $a_{1}$ & -5.62474 & 2.95902 & 1.89246 & 1.22769 \\
\hline & $\mathrm{a}_{2}$ & 2.90657 & -1.02961 & -0.65730 & -0.69910 \\
\hline & $a_{3}$ & 0 & 0 & 0 & 0.12572 \\
\hline \multirow[t]{4}{*}{ (Sn) } & $a_{0}$ & 5.81221 & 1.16583 & 2.51483 & - \\
\hline & $a_{1}$ & -10.28471 & -1.58597 & -3.70248 & - \\
\hline & $\mathrm{a}_{2}$ & 4.47257 & 0.32533 & 1.25412 & - \\
\hline & $a_{3}$ & 0 & 0.09524 & 0 & - \\
\hline \multirow[t]{4}{*}{ (In) } & $a_{0}$ & 6.27651 & 1.63789 & - & - \\
\hline & $a_{1}$ & -11.02034 & -2.30234 & - & - \\
\hline & $\mathrm{a}_{2}$ & 4.74377 & 0.53851 & - & - \\
\hline & $a_{3}$ & 0 & 0.12609 & - & - \\
\hline \multirow{3}{*}{ (Ga) } & $a_{0}$ & 5.06768 & - & - & - \\
\hline & $a_{1}$ & -9.84880 & - & - & - \\
\hline & $\mathrm{a}_{2}$ & 4.78109 & - & - & - \\
\hline \multirow[t]{3}{*}{ (Hg) } & $a_{0}$ & -23.00990 & - & - & - \\
\hline & $a_{1}$ & 43.27748 & - & - & - \\
\hline & $a_{2}$ & -20.26770 & - & - & - \\
\hline
\end{tabular}

In order to find the best available estimates of the correction $C_{\mathrm{NU}-1}$ and its uncertainty, we calculated the sample mean $M_{\mathrm{NU}-1}^{\left(S_{j}\right)}$, (equation (19)) and, respectively, the experimental standard deviation $s\left(C_{\mathrm{NU}-1}^{(S j)}\right)$ (equation (20)). Their extreme values for the investigated sample, determined for each calibration subrange, are listed in Table 3, along with the maximum and the minimum values of $C_{\mathrm{NU}-1}^{\left(S_{j}\right)}$.

A simple graphical verification (Appendix B, Figure B.2) shows that the results obtained after the correction for the effect of the Type 1 non-uniqueness in the different subranges that overlap are consistent (they agree) within their uncertainties calculated for a level of confidence of $95 \%$.

$W$-dependent polynomial curves

$$
M_{\mathrm{NU}-1}^{(S j)} / \mathrm{mK}=\sum_{i=0}^{3} \mathrm{a}_{i} W^{i}
$$

were fitted to the experimental curves, based on the method of least squares $\left(r^{2} \geq 0.9964\right)$. The coefficients $\mathrm{a}_{i}$ are given in Table 4 and they can be used to predict the values of the input quantity $C_{\mathrm{NU}-1}^{\left(S_{j}\right)}$ in the model (17) for each $W$ of 
Table 5. Coefficients of equation (22) for each region of overlap.

\begin{tabular}{|c|c|c|c|c|c|}
\hline Subrange $S_{j}$ & $\mathrm{~b}_{i} / \mathrm{mK}$ & $\begin{array}{l}\text { Region } 1 \text { : } \\
0^{\circ} \mathrm{C} \text { to } \\
29.7646^{\circ} \mathrm{C}\end{array}$ & $\begin{array}{c}\text { Region 2: } \\
29.7646^{\circ} \mathrm{C} \text { to } \\
156.5985^{\circ} \mathrm{C}\end{array}$ & $\begin{array}{c}\text { Region 3: } \\
156.5985^{\circ} \mathrm{C} \text { to } \\
231.928^{\circ} \mathrm{C}\end{array}$ & $\begin{array}{c}\text { Region } 4: \\
231.928^{\circ} \mathrm{C} \text { to } \\
419.527^{\circ} \mathrm{C}\end{array}$ \\
\hline \multirow[t]{4}{*}{$\overline{(\mathrm{Al})}$} & $\mathrm{b}_{0}$ & -4.16468 & -4.43077 & -0.93452 & 3.37742 \\
\hline & $b_{1}$ & 6.91784 & 8.29991 & 1.76941 & -6.10544 \\
\hline & $b_{2}$ & -2.75304 & -4.71149 & -0.67406 & 3.45339 \\
\hline & $b_{3}$ & 0 & 0.83932 & 0 & -0.61836 \\
\hline \multirow[t]{4}{*}{ (Zn) } & $b_{0}$ & -0.56614 & -1.15597 & -1.29742 & 3.37740 \\
\hline & $b_{1}$ & 0.56616 & 1.68686 & 2.05838 & -6.10541 \\
\hline & $b_{2}$ & 0 & -0.52902 & -0.72537 & 3.45338 \\
\hline & $b_{3}$ & 0 & 0 & 0 & -0.61835 \\
\hline \multirow[t]{3}{*}{ (Sn) } & $\mathrm{b}_{0}$ & -2.92848 & -2.77735 & -2.85058 & - \\
\hline & $b_{1}$ & 4.42524 & 4.30589 & 4.31260 & - \\
\hline & $\mathrm{b}_{2}$ & -1.49671 & -1.53088 & -1.48278 & - \\
\hline \multirow[t]{5}{*}{ (In) } & $\mathrm{b}_{0}$ & -1.16105 & 6.45881 & - & - \\
\hline & $b_{1}$ & 1.42413 & -25.16828 & - & - \\
\hline & $b_{2}$ & -0.26302 & 34.37591 & - & - \\
\hline & $b_{3}$ & 0 & -19.77178 & - & - \\
\hline & $\mathrm{b}_{4}$ & 0 & 4.11623 & - & - \\
\hline \multirow[t]{3}{*}{ (Ga) } & $b_{0}$ & -0.34626 & - & - & - \\
\hline & $b_{1}$ & 0.11258 & - & - & - \\
\hline & $b_{2}$ & 0.23369 & - & - & - \\
\hline \multirow[t]{4}{*}{$(\mathrm{Hg})$} & $b_{0}$ & -43.63823 & - & - & - \\
\hline & $b_{1}$ & 121.84541 & - & - & - \\
\hline & $b_{2}$ & -113.69715 & - & - & - \\
\hline & $b_{3}$ & 35.48970 & - & - & - \\
\hline
\end{tabular}

the regions of overlap. The $M_{\mathrm{NU}-1}^{\left(S_{j}\right)}$ values are graphically represented as a function of temperature in Appendix B, Figure B.1.

$W$-dependent polynomial curves in analytical form

$$
s\left(C_{\mathrm{NU}-1}^{\left(S_{j}\right)}\right) / \mathrm{mK}=\sum_{i=0}^{4} \mathrm{~b}_{i} W^{i}
$$

were fitted to the experimental curves by the least squares method $\left(r^{2} \geq 0.99996\right)$. The coefficients $\mathrm{b}_{i}$ are presented in Table 5 and they can be used to predict the values of the standard uncertainty associated with $C_{\mathrm{NU}-1}^{\left(S_{j}\right)}$ for each $W$ of the regions of overlap.

When calibrations are made according to the ITS-90, the estimate of $C_{\mathrm{NU}-1}$ at any $W$ can be quickly and easily obtained by equation (21) (using Table 4) and then introduced in the model (17) to calculate the estimate of the measurand. Also, the standard uncertainty s $\left(C_{\mathrm{NU}-1}\right)$ can be calculated by equation (22) (using Table 5 ) and then used to evaluate - by means of the same model (17) - the "uncertainty in knowing the measurand" [25].

The most important finding of this section relates to the standard uncertainty associated with the effect of the Type 1 non-uniqueness of the Scale. Its values determined for each $W$ of the regions of overlap of the six subranges do not exceed $0.26 \mathrm{mK}$ and they are up to 5 times smaller than the values given for the subrange 0 to $420^{\circ} \mathrm{C}$ in the specific Guides developed by the CCT [3,11].

A notable example is the (Ga) sub-range of the ITS-90, which was designed to achieve "the highest accuracy thermometry in the range room temperature" [29]. It should be noted that the values of the standard uncertainty declared in Annex $\mathrm{C}$ of KCDB by the laboratories participating in CCT-K3 are really small at the melting point of gallium: their average is about $0.12 \mathrm{mK}$, and two values are smaller even than $0.1 \mathrm{mK}(0.035 \mathrm{mK}$, and, respectively, $0.07 \mathrm{mK})$. The standard uncertainty in knowing the Type 1 non-uniqueness at the Ga point determined by applying the method proposed here for the (Ga) subrange is also very small: $0.072 \mathrm{mK}$; the value derived by applying the method developed in the Guides of the CCT [3,11] is equal to $0,265 \mathrm{mK}$.

Another relevant example: in the region where only the (Al) and (Zn) subranges overlap - from $232^{\circ} \mathrm{C}$ to $420^{\circ} \mathrm{C}-$, the ratio of the uncertainties calculated by the two methods is also equal to 1:4.

\subsection{The case of the Simple Type 1 non-uniqueness}

As shown in Section 3, the Simple Type 1 non-uniqueness is not relevant for the evaluation of the uncertainty in realising the ITS-90. However, the most important 
Table 6. Descriptive statistics for the Simple Type 1 non-uniqueness.

\begin{tabular}{lllllll}
\hline $\begin{array}{l}\text { Pairs of } \\
\text { overlapping } \\
\text { subranges }\end{array}$ & Sample size, $n$ & $\begin{array}{l}\text { Maximum } \\
\text { of } \\
M / \mathrm{mK}\end{array}$ & $\begin{array}{l}\text { Minimum } \\
\text { of } \\
M / \mathrm{mK}\end{array}$ & $\begin{array}{l}\text { Maximum } \\
\text { of } \\
\mathrm{ESD} / \mathrm{mK}\end{array}$ & $\begin{array}{l}\text { Maximum } \\
\text { of } \\
\text { NU-1/mK }\end{array}$ & $\begin{array}{l}\text { Minimum } \\
\text { of } \\
\text { NU-1/mK }\end{array}$ \\
\hline$(\mathrm{Al}-\mathrm{Zn})$ & 21 & 0.039 & -0.026 & 0.220 & 0.472 & -0.352 \\
$(\mathrm{Al}-\mathrm{Sn})$ & 19 & 0.000 & -0.160 & 0.715 & 2.123 & -1.364 \\
$(\mathrm{Al}-\mathrm{In})$ & 19 & 0.000 & -0.254 & 0.621 & 1.859 & -1.291 \\
$(\mathrm{Al}-\mathrm{Ga})$ & 21 & 0.016 & -0.001 & 0.152 & 0.459 & -0.230 \\
$(\mathrm{Al}-\mathrm{Hg})$ & 18 & 0.092 & 0.000 & 0.161 & 0.459 & -0.230 \\
$(\mathrm{Zn}-\mathrm{Sn})$ & 23 & 0.000 & -0.173 & 0.658 & 2.099 & -1.077 \\
$(\mathrm{Zn}-\mathrm{In})$ & 23 & 0.000 & -0.260 & 0.578 & 1.841 & -1.012 \\
$(\mathrm{Zn}-\mathrm{Ga})$ & 25 & 0.000 & -0.016 & 0.136 & 0.239 & -0.329 \\
$(\mathrm{Zn}-\mathrm{Hg})$ & 22 & 0.064 & -0.010 & 0.144 & 0.244 & -0.329 \\
$(\mathrm{Sn}-\mathrm{In})$ & 23 & 0.000 & -0.097 & 0.322 & 0.379 & -1.177 \\
$(\mathrm{Sn}-\mathrm{Ga})$ & 23 & 0.066 & 0.000 & 0.288 & 0.633 & -0.794 \\
$(\mathrm{Sn}-\mathrm{Hg})$ & 22 & 0.114 & 0.000 & 0.292 & 0.633 & -0.794 \\
$(\mathrm{In}-\mathrm{Ga})$ & 23 & 0.103 & 0.000 & 0.204 & 0.459 & -0.279 \\
$(\mathrm{In}-\mathrm{Hg})$ & 22 & 0.152 & 0.000 & 0.195 & 0.459 & -0.287 \\
$(\mathrm{Ga}-\mathrm{Hg})$ & 22 & 0.084 & 0.000 & 0.030 & 0.124 & -0.007 \\
\hline
\end{tabular}

statistics on NU-1 derived from CCT-K3 are shown in Table 6 in order to make possible their comparison with the results of the studies published so far, on the one hand and to provide a comprehensive view of the subject, on the other hand. Since the existence of the outliers has not been verified, it is highly possible that such values exist among the data presented.

It should be noted that little information is available in the specific literature concerning the estimate of Type 1 non-uniqueness. Most of it $[9,10]$ refer to the $(\mathrm{Al}-\mathrm{Zn})$ pair and indicate the maximum values of the sample mean $(M)$ and the experimental standard deviation (ESD or s). The maximum value of the ESD calculated here $(0.220 \mathrm{mK}$, Table 6), is 1.4 times lower than the maximum value in [9] $(0.3161 \mathrm{mK})$ and, respectively, 2 times lower than the one in [10] $(0.48 \mathrm{mK})$. The maximum value of $M$ in Table 6 $(0.039 \mathrm{mK})$ is also smaller than the values in [9] $(0.0575 \mathrm{mK})$ and [10] $(0.12 \mathrm{mK})$.

The Table 6 also shows that the largest dispersions occur for the combinations (Al-Sn), (Al-In), (Zn-Sn) and (Zn-In), whereas, for the (Al-Zn) pair, the sample standard deviation is almost 3 times lower. Similar proportions can be also found between the dispersions calculated in [12] and [9].

The Simple Type 1 non-uniqueness curves determined for all of the 15 overlapping subranges pairs above $0^{\circ} \mathrm{C}$ are graphically represented as a function of temperature in Appendix B, Figure B.3.

\section{What generates the Type 1 non- uniqueness of the Scale? Final analysis}

The models proposed in previous sections allow us to single out and analyse the factors that generate Type 1 nonuniqueness of the Scale and influence its value.
As we have already shown, for a given $W$, the Type 1 non-uniqueness and the correction $C_{\mathrm{NU}-1^{-}}$both of them hereafter in this section generically referred to as "nonuniqueness" - are explicit functions of the deviations $\Delta \mathrm{W}_{\mathrm{FP}}=\mathrm{W}_{\mathrm{FP}}-\mathrm{W}_{\mathrm{r}, \mathrm{FP}}$ and of the corresponding propagation functions. We recall briefly here that the propagation functions, in their turn, depend on the resistances ratio $W$ and on its values at fixed points, $W_{\mathrm{FP}}$. If we substitute $W_{\mathrm{FP}} \cong W_{\mathrm{r}, \mathrm{FP}}-$ substitution that influences the nonuniqueness values by less than $1 \mu \mathrm{K}$ - the propagation functions will depend on a single variable, namely on $W$; and for a given $W$, any function of propagation becomes a constant. Consequently, the non-uniqueness calculated for a given $W$ will be function of only the deviations $\Delta W_{\mathrm{FP}}$.

The $\Delta W_{\mathrm{FP}}$ values are, evidently, inextricably linked to all the factors that influence the $W_{\mathrm{FP}}$ values $^{5}$, that is $[3,29,30]:$

- the construction of the SPRT. The defects or the irregularities in the crystalline structure of platinum (the impurities, first of all) that alter its electrical and thermal properties, the immersion characteristic, the internal self heating phenomenon, the mechanical strains in the platinum resistor, the partial pressure of oxygen in the thermometer, the radiation piping, the electrical leakage across the insulators, etc. can influence the value of non-uniqueness;

- the realisation of the defining fixed points of the ITS-90. The impurities in the fixed point substance, the isotopic composition of water, the hydrostatic head of liquid in the cell, the deviation of the pressure of gas in the fixed point cell from the Reference pressure, the stray heat transfer, the external self heating phenomenon, etc., can be also responsible for the value of non-uniqueness;

\footnotetext{
${ }_{5}^{5}$ Even if corrections are applied to compensate for some systematic effects, the compensation of the effects is imperfect.
} 
- the measurement of the electrical resistance of SPRT. In their turn, the variation of the reference resistance against the temperature, the stability of the measuring current, the nonlinearity of the bridge, the noise, and so on, can contribute to non-uniqueness.

But the dependency of the non-uniqueness on the deviations $\Delta W_{\mathrm{FP}}$ should not be understood strictly in the sense that the non-uniqueness is larger if the values of $\Delta W_{\mathrm{FP}}$ are larger. Non-uniqueness also depends on the relation that exists between the values of $\Delta W_{\mathrm{FP}}$ at the fixed points involved. An illuminating example is the Simple Type 1 nonuniqueness between subranges (In) and (Ga) (Appendix A)

$$
(\mathrm{NU}-1)^{(\mathrm{In}-\mathrm{Ga})}=f_{\mathrm{Ga}}^{(\mathrm{Ga})} \Delta W_{\mathrm{Ga}}-f_{\mathrm{In}}^{(\mathrm{In})} \Delta W_{\mathrm{In}},
$$

where $f_{\mathrm{Ga}}^{(\mathrm{Ga})}=\frac{W-1}{W_{\mathrm{r}, \mathrm{Ga}}-1}$ and $f_{\mathrm{In}}^{(\mathrm{In})}=\frac{W-1}{W_{\mathrm{r}, \mathrm{In}}-1}$. As a result, between subranges $(\mathrm{In})$ and $(\mathrm{Ga})$ there is no Type 1 non-uniqueness only if between $\Delta W_{\mathrm{In}}$ and $\Delta W_{\mathrm{Ga}}$ there is the relation

$$
\begin{aligned}
\Delta W_{\mathrm{In}} & =\frac{f_{\mathrm{Ga}}^{(\mathrm{Ga})}}{f_{\mathrm{In}}^{(\mathrm{In})}} \Delta W_{\mathrm{Ga}}=\frac{W_{\mathrm{r}, \mathrm{In}}-1}{W_{\mathrm{r}, \mathrm{Ga}}-1} \Delta W_{\mathrm{Ga}} \\
& =5.1617 \times \Delta W_{\mathrm{Ga}},
\end{aligned}
$$

regardless of whether the values of $\Delta W_{\mathrm{Ga}}$ and $\Delta W_{\mathrm{In}}$ are large or small. For a given SPRT, any change in the ratio between $\Delta W_{\text {In }}$ and $\Delta W_{\mathrm{Ga}}$, generated by the local imperfections in the realisation of the two fixed points and/or in the measurement of the electrical resistance, determine a change of the NU-1 value.

The relationship between $\Delta W_{\mathrm{In}}$ and $\Delta W_{\mathrm{Ga}}$ in (24) is simple and it does not depend on $W$. A similar case is the Simple Type 1 non-uniqueness between subranges (Sn) and (In), where the relation between $\Delta W_{\mathrm{Sn}}$ and $\Delta W_{\text {In }}$ for zero Type 1 non-uniqueness is given by

$$
\begin{aligned}
\Delta W_{\mathrm{Sn}} & =-\frac{f_{\mathrm{In}}^{(\mathrm{Sn})}-f_{\mathrm{In}}^{(\mathrm{In})}}{f_{\mathrm{Sn}}^{(\mathrm{Sn})}} \Delta W_{\mathrm{In}}=\frac{W_{\mathrm{r}, \mathrm{Sn}}-1}{W_{\mathrm{r}, \mathrm{In}}-1} \Delta W_{\mathrm{In}} \\
& =1.4641 \times \Delta W_{\text {In }}
\end{aligned}
$$

or the case of the Simple Type 1 non-uniqueness between subranges $(\mathrm{Ga})$ and $(\mathrm{Hg})$, where

$$
\begin{aligned}
\Delta W_{\mathrm{Ga}} & =-\frac{f_{\mathrm{Hg}}^{(\mathrm{Hg})}}{f_{\mathrm{Ga}}^{(\mathrm{Ga})}-f_{\mathrm{Ga}}^{(\mathrm{Hg})}} \Delta W_{\mathrm{Hg}} \\
& =-\frac{W_{\mathrm{r}, \mathrm{Ga}}-1}{W_{\mathrm{r}, \mathrm{Hg}}-1} \Delta W_{\mathrm{Hg}}=0.7580 \times \Delta W_{\mathrm{Hg}}
\end{aligned}
$$

for zero Type 1 non-uniqueness.

For pairs of overlapping subranges with 3 up to 5 independent variables $\Delta W_{\mathrm{FP} k}$, the condition of zero $N U-1$ leads to more complicated relations, because the value of the deviation at a fixed point depends on the values of the deviation at other two, three or four fixed points simultaneously.

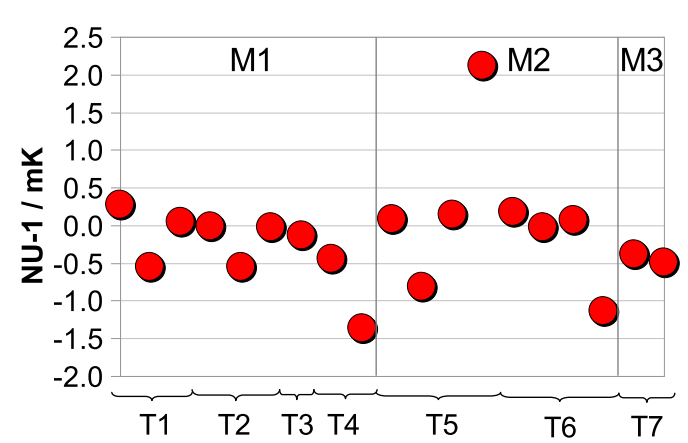

Fig. 1. The values of the Simple NU-1 for the pair (Al-Sn). T calibrated thermometer; $\mathrm{M}$ - thermometer model.

We can say that the non-uniqueness derives from the fact that the $\Delta W_{\mathrm{FP} k}$ values - determined during calibrations - do not fit into the relationship between them imposed by interpolation equations (by means of the propagation functions).

It is obvious that non-uniqueness is zero if all deviations determined at fixed points involved are equal to zero, i.e. when the $W_{\mathrm{FP}}$ values are equal to the $W_{\text {r.FP }}$ values (the latter being the $W_{\mathrm{FP}}$ values of SPRT used by the designers of the ITS-90).

The advantage of an inter-laboratory comparison is that it reveals similarities and differences among values and it helps in understanding the causes. An example is illustrated in Figure 1, that represents the values of the Simple Type 1 non-uniqueness at a given $W$ between subranges $(\mathrm{Al})$ and $(\mathrm{Sn})$, derived from the results of the CCT-K3. Each CCT-K3 loop is designated by the calibrated thermometer $(\mathrm{T})$ and the loops are grouped according to the thermometer model: M1, M2 and M3.

It is easy to see that:

- the NU-1 values in a loop differ among them, although the laboratories had calibrated the same thermometer;

- the sets of NU-1 values in the different loops are somewhat similar, although another SPRT had been calibrated within each loop; in each loop there is at least one laboratory with values of NU-1 that differ significantly from others.

The differences between the values in the same loop could only to a small extent be due to the thermometer, because one should suppose that most of the influence quantities related to the construction of the SPRT have approximately the same impact upon the measurement results in each laboratory of the loop (see the internal self heating effect, for instance, if the same measuring current is used). It can be deduced from here that the differences are due rather to the problems related to the realisation of fixed points (most probable, they are caused by impurities in the substance fixed point) and/or to the measurement of the electrical resistance of SPRT.

The sets of values surprisingly similar of NU-1 in different loops could also indicate a reduced contribution of the effects related to the construction of the thermometers compared to the other causes. 


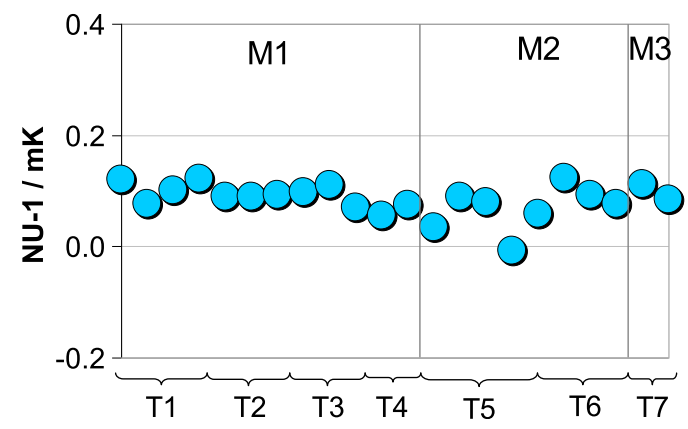

Fig. 2. The values of the Simple NU-1 for the pair (Ga-Hg). T calibrated thermometer; $\mathrm{M}$ - thermometer model.

If the dominant factor is the design of the SPRT, then the values of NU-1 in a loop should be close enough one to the other. Such seems to be the case with the pair ( $\mathrm{Ga}-\mathrm{Hg}$ ) in Figure 2: the values of the NU-1 in each loop differ from one another by only several tens of microkelvins, and the differences between the NU-1 values in different loops have the same order of magnitude. The explanation could lie in the very small errors that generally occur in the realisation of the two fixed points involved, $\mathrm{Ga}$ and $\mathrm{Hg}$. Moreover, similar values in different loops might indicate that the influence of the SPRT construction upon the values of the NU-1 is insignificantly different from one thermometer to another at these temperatures.

An interesting segregation of the values of $\Delta W_{\mathrm{FP}}$ according to the SPRT models can be seen in Figure 3, where there are represented the deviations $\Delta W_{\mathrm{FP}}$ determined by the participating laboratories using the 7 SPRTs: 4 Model M1, 2 Model M2 and 1 Model M3. The chart shows the distinct groups of values that have been formed depending on the model. This clear separation into three groups cannot be explained only through the different quality of the platinum used in the three models as it is hard to believe that the manufacturers of SPRTs use platinum so different, but also through the other construction elements and through the technology used in the manufacturing process. It should be noted the narrow range of the $\Delta W_{\mathrm{FP}}$ values at the points $\mathrm{Hg}(\approx 3 \mathrm{mK})$ and $\mathrm{Ga}$ $(\approx 2.5 \mathrm{mK})$, which increases gradually but substantially at the other fixed points.

Although the difference between the deviations $\Delta W_{\mathrm{Al}}$ determined using models M1 and M3 can reach approximately $57 \mathrm{mK}$ (Figure 3), the values of Type 1 nonuniqueness associated with the two models differ by much less than that. This is yet another confirmation of the fact that non-uniqueness depends on the relation that exists between the experimentally determined deviations for a given subrange (not only on the magnitude of these values) versus the relation prescribed by the Scale equation (corresponding to the reference SPRT).

\section{Conclusions}

Much of the interest in the Type 1 non-uniqueness of the Scale concerns its influence on the results of calibration of the SPRTs performed according to the ITS-90. The new approach described in this study diverges considerably

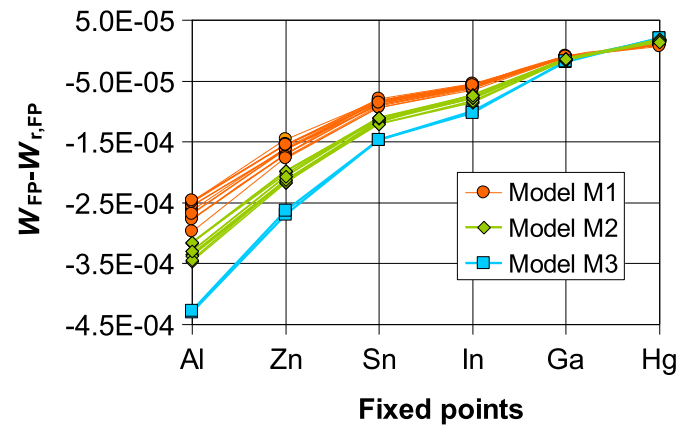

Fig. 3. The values $\Delta W_{\mathrm{FP}}$ determined at the temperatures of fixed points using the three models of SPRT: M1 (circles), M2 (diamonds), and M3 (squares).

from the current approach. Therefore, it is not surprising that the results differ significantly from those published so far. A notable example is that the values of standard uncertainty assessed by the novel methodology for each region of overlap of the six calibration subranges do not exceed $0.26 \mathrm{mK}$ and they are up to 5 times smaller than the values specified in the Guides developed by the CCT $[3,11]$.

A value diminished of an component will be reflected in a reduction of the combined standard uncertainty itself, i.e. a diminution of the uncertainty in realising the ITS-90 and, thus, a diminution of the uncertainty of all measurement results that are metrologically traceable to the Scale realised.

The values determined in this study for the input quantity $C_{\mathrm{NU}-1}$ and its uncertainty are applicable to all measurement models when calibrations according to the ITS-90 are performed in any of the subranges between $0{ }^{\circ} \mathrm{C}$ and $962^{\circ} \mathrm{C}$.

The concepts and methods introduced here for the temperature subranges above $0{ }^{\circ} \mathrm{C}$ can also be developed without difficulty and used to study the Type 1 nonuniqueness of the Scale in the temperature subranges below $0{ }^{\circ} \mathrm{C}$.

\section{References}

1. H. Preston-Thomas, Metrologia 27, 3 (1990)

2. B.W. Mangum et al., Metrologia 34, 427 (1997)

3. Consultative Committee for Thermometry, Guide to the Realization of the ITS-90, CCT Publication (2015-2016), available at http://www.bipm.org/en/committees/cc/cct/ guide-its90.html

4. K.D. Hill, R.E. Bedford, CCT working document CCT/89-6 (1989)

5. L. Crovini, in Proceedings of the 7 th International Temperature Symposium on Temperature: Its Measurement and Control in Science and Industry, 1992, edited by J.F. Schooley (American Institute of Physics, New York, 1993), p. 139

6. G.F. Strouse, in Proceedings of the 7th International Temperature Symposium on Temperature: Its Measurement and Control in Science and Industry, 1992, edited by J.F. Schooley (American Institute of Physics, New York, 1993), p. 165 
7. N.P. Moiseeva, A.I. Pokhodun, in Proceedings of the 7th International Temperature Symposium on Temperature: Its Measurement and Control in Science and Industry, 1992, edited by J.F. Schooley (American Institute of Physics, New York, 1993), p. 187

8. M.G. Ahmed, in Proceedings TEMPMEKO 2004 of the 9th International Symposium on Temperature and Thermal Measurements in Industry and Science, Cavtat 2004, edited by D. Zvizdic (Laboratory for Process Measurement, Faculty of Mechanical Engineering and Naval Architecture, Zagreb, 2005), p. 271

9. K. Zhiru, L. Jingbo, L. Xiaoting, Metrologia 39, 127 (2002)

10. D.R. White, G.F. Strouse, Metrologia 46, 101 (2009)

11. D.R. White et al., Uncertainties in the realisation of the SPRT subranges of the ITS-90, 24th CCT meeting working document CCT/08-19/rev2, BIPM (2014), available at http://www.bipm.org/cc/CCT/Allowed/24/ Uncert_CCT-08-19-rev-2014-01-24.pdf

12. Z. Kang, J. Lan, J. Zhang, K.D. Hill, J. Sun, J. Chen, Int. J. Thermophys. 32, 68 (2011)

13. Z. Kang, J. Lan, C. Liu, U. Noatsch, J. Sun, S. Chen, in Proceedings of the 9th International Temperature Symposium on Temperature: Its Measurement and Control in Science and Industry vol. 8, Los Angeles, 2012, edited by C. W. Meyer (American Institute of Physics, New York, 2013), p. 94

14. K.D. Hill, Metrologia 32, 87 (1995)

15. A.G. Steele, Metrologia 42, 289 (2005)

16. C.W. Meyer, W.L. Tew, Metrologia 43, 341 (2006)

17. J.P. Sun, J.T. Zhang, Z.R. Kang, Y. Duan, Int. J. Thermophys. 31, 1789 (2010)

18. Z. Kang, J. Lan, Y. Duan, J.T. Zhang, B. Thiele-Krivoi, S. Chen, H. Zhang, in Proceedings of the 9th International Temperature Symposium on Temperature: Its Measurement and Control in Science and Industry vol. 8, Los Angeles, 2012, edited by C. W. Meyer (American Institute of Physics, New York, 2013), p. 100

19. B.W. Mangum, G.F. Strouse, W.F. Guthrie, CCT-K3: key Comparison of Realizations of the ITS-90 over the range 83, $8058 \mathrm{~K}$ to 933, $473 \mathrm{~K}$, NIST Technical Note 1450 (US Government Printing Office, Washington, 2002)

20. S. Gaita, C. Iliescu, in Proceedings of the International Metrology Conference (Bucharest, 2001), Vol. 1, p. 129

21. S. Gaita, C. Iliescu, in Proceedings of the International Metrology Conference (Bucharest, 2001), Vol. 1, p. 135

22. S. Gaita, in Proceedings of the 10th International Metrology Congress (Saint-Louis, 2001) (Mouvement français pour la Qualité, Montpellier)

23. M. Sadli, E. Renaot, G. Bonnier, in Proceedings of the EUROMET Workshop in Temperature (Paris, 1998), p. 7

24. JCGM, Evaluation of measurement data - Guide to the expression of uncertainty in measurement, JCGM 100:2008, Joint Committee for Guides in Metrology, available at http://www.bipm.org/en/publications/guides/

25. I. Lira, Evaluating the measurement uncertainty. Fundamentals and practical guidance, edited by $\mathrm{M}$. Afsar (Institute of Physics Publishing, Bristol, UK, 2002)

26. J.W. Tukey, Exploratory Data Analysis (Addison-Wesley, Reading, Massachusetts, USA, 1977)

27. S.S. Shapiro, M.B. Wilk, Biometrika 52, 591 (1965)

28. F.E. Grubbs, Technometrics 11, 1 (1969)

29. BIPM Supplementary information for the International Temperature Scale of 1990 (ITS-90), (BIPM, Sèvres, 1997) available at http://www.bipm.org/en/committees/cc/cct/ guide-its90.html

30. D.R. White et al., Int. J. Thermophys. 31, 1749 (2010)

31. R. Willink, Int. J. Metrol. Qual. Eng. 3, 169 (2012)

32. F. Pavese, Int. J. Metrol. Qual. Eng. 3, 155 (2012) 


\section{Appendices}

Appendix A: Formulas for The Simple Type 1 non-uniqueness and the Correction $C_{\mathrm{NU}-1}$ A.1 The deviation functions and their propagation functions

- From $0^{\circ} \mathrm{C}$ to $660.323^{\circ} \mathrm{C}$ :

$$
\Delta W^{(\mathrm{Al})}=f_{\mathrm{Sn}}^{(\mathrm{Al})} \Delta W_{\mathrm{Sn}}+f_{\mathrm{Zn}}^{(\mathrm{Al})} \Delta W_{\mathrm{Zn}}+f_{\mathrm{Al}}^{(\mathrm{Al})} \Delta W_{\mathrm{Al}}
$$

where

$$
\begin{aligned}
& f_{\mathrm{Sn}}^{(\mathrm{Al})}=\frac{(W-1)\left(W-W_{\mathrm{Zn}}\right)\left(W-W_{\mathrm{Al}}\right)}{\left(\mathrm{W}_{\mathrm{Sn}}-1\right)\left(W_{\mathrm{Sn}}-W_{\mathrm{Zn}}\right)\left(W_{\mathrm{Sn}}-W_{\mathrm{Al}}\right)}, \\
& f_{\mathrm{Zn}}^{(\mathrm{Al})}=\frac{(W-1)\left(W-W_{\mathrm{Sn}}\right)\left(W-W_{\mathrm{Al}}\right)}{\left(W_{\mathrm{Zn}}-1\right)\left(W_{\mathrm{Zn}}-W_{\mathrm{Sn}}\right)\left(W_{\mathrm{Zn}}-W_{\mathrm{Al}}\right)},
\end{aligned}
$$

and

$$
f_{\mathrm{Al}}^{(\mathrm{Al})}=\frac{(W-1)\left(W-W_{\mathrm{Sn}}\right)\left(W-W_{\mathrm{Zn}}\right)}{\left(W_{\mathrm{Al}}-1\right)\left(W_{\mathrm{Al}}-W_{\mathrm{Sn}}\right)\left(W_{\mathrm{Al}}-W_{\mathrm{Zn}}\right)} .
$$

- From $0^{\circ} \mathrm{C}$ to $419.527^{\circ} \mathrm{C}$ :

$$
\Delta W^{(\mathrm{Zn})}=f_{\mathrm{Sn}}^{(\mathrm{Zn})} \Delta W_{\mathrm{Sn}}+f_{\mathrm{Zn}}^{(\mathrm{Zn})} \Delta W_{\mathrm{Zn}}
$$

where

$$
f_{\mathrm{Sn}}^{(\mathrm{Zn})}=\frac{(W-1)\left(W-W_{\mathrm{Zn}}\right)}{\left(\mathrm{W}_{\mathrm{Sn}}-1\right)\left(W_{\mathrm{Sn}}-W_{\mathrm{Zn}}\right)}
$$

and

$$
f_{\mathrm{Zn}}^{(\mathrm{Zn})}=\frac{(W-1)\left(W-W_{\mathrm{Sn}}\right)}{\left(W_{\mathrm{Zn}}-1\right)\left(W_{\mathrm{Zn}}-W_{\mathrm{Sn}}\right)}
$$

- From $0^{\circ} \mathrm{C}$ to $231.928^{\circ} \mathrm{C}$ :

$$
\Delta W^{(\mathrm{Sn})}=f_{\mathrm{In}}^{(\mathrm{Sn})} \Delta W_{\mathrm{In}}+f_{\mathrm{Sn}}^{(\mathrm{Sn})} \Delta W_{\mathrm{Sn}},
$$

where

$$
f_{\mathrm{In}}^{(\mathrm{Sn})}=\frac{(W-1)\left(W-W_{\mathrm{Sn}}\right)}{\left(\mathrm{W}_{\mathrm{In}}-1\right)\left(W_{\mathrm{In}}-W_{\mathrm{Sn}}\right)}
$$

and

$$
f_{\mathrm{Sn}}^{(\mathrm{Sn})}=\frac{(W-1)\left(W-W_{\mathrm{In}}\right)}{\left(W_{\mathrm{Sn}}-1\right)\left(W_{\mathrm{Sn}}-W_{\mathrm{In}}\right)} .
$$

- From $0{ }^{\circ} \mathrm{C}$ to $156.5985^{\circ} \mathrm{C}$ :

$$
\Delta W^{(\mathrm{In})}=f_{\mathrm{In}}^{(\mathrm{In})} \Delta W_{\mathrm{In}},
$$

where

$$
f_{\text {In }}^{(\mathrm{In})}=\frac{(W-1)}{\left(\mathrm{W}_{\mathrm{In}}-1\right)} .
$$


- From $0{ }^{\circ} \mathrm{C}$ to $29.7646{ }^{\circ} \mathrm{C}$ :

$$
\Delta W^{(\mathrm{Ga})}=f_{\mathrm{Ga}}^{(\mathrm{Ga})} \Delta W_{\mathrm{Ga}}
$$

where

$$
f_{\mathrm{Ga}}^{(\mathrm{Ga})}=\frac{(W-1)}{\left(\mathrm{W}_{\mathrm{Ga}}-1\right)}
$$

- From $-38.8344^{\circ} \mathrm{C}$ to $29.7646^{\circ} \mathrm{C}$ :

$$
\Delta W^{(\mathrm{Hg})}=f_{\mathrm{Ga}}^{(\mathrm{Hg})} \Delta W_{\mathrm{Ga}}+f_{\mathrm{Hg}}^{(\mathrm{Hg})} \Delta W_{\mathrm{Hg}},
$$

where

$$
f_{\mathrm{Hg}}^{(\mathrm{Hg})}=\frac{(W-1)\left(W-W_{\mathrm{Ga}}\right)}{\left(W_{\mathrm{Hg}}-1\right)\left(W_{\mathrm{Hg}}-W_{\mathrm{Ga}}\right)}
$$

and

$$
f_{\mathrm{Ga}}^{(\mathrm{Hg})}=\frac{(W-1)\left(W-W_{\mathrm{Hg}}\right)}{\left(W_{\mathrm{Ga}}-1\right)\left(W_{\mathrm{Ga}}-W_{\mathrm{Hg}}\right)} .
$$

\section{A.2 The Simple Type 1 non-uniqueness and the combined propagation functions}

- (Al-Zn)

$$
\begin{aligned}
(\mathrm{NU}-1)^{(\mathrm{Al}-\mathrm{Zn})} & =g_{\mathrm{Sn}}^{(\mathrm{Al}-\mathrm{Zn})} \Delta W_{\mathrm{Sn}}+g_{\mathrm{Zn}}^{(\mathrm{Al}-\mathrm{Zn})} \Delta W_{\mathrm{Zn}}+g_{\mathrm{Al}}^{(\mathrm{Al}-\mathrm{Zn})} \Delta W_{\mathrm{A} 1} \\
& =\left(-f_{\mathrm{Sn}}^{(\mathrm{Al})}+f_{\mathrm{Sn}}^{(\mathrm{Zn})} \Delta W_{\mathrm{Sn}}+\left(-f_{\mathrm{Zn}}^{(\mathrm{Al})}+f_{\mathrm{Zn}}^{(\mathrm{Zn})}\right) \Delta W_{\mathrm{Zn}}-f_{\mathrm{Al}}^{(\mathrm{Al})} \Delta W_{\mathrm{Al}}\right.
\end{aligned}
$$

where

$$
g_{\mathrm{Sn}}^{(\mathrm{Al}-\mathrm{Zn})}=-f_{\mathrm{Sn}}^{(\mathrm{Al})}+f_{\mathrm{Sn}}^{(\mathrm{Zn})}=-\frac{(W-1)\left(W-W_{\mathrm{Sn}}\right)\left(W-W_{\mathrm{Zn}}\right)}{\left(\mathrm{W}_{\mathrm{Sn}}-1\right)\left(W_{\mathrm{Sn}}-W_{\mathrm{Zn}}\right)\left(W_{\mathrm{Sn}}-W_{\mathrm{Al}}\right)}
$$

and

$$
g_{\mathrm{Zn}}^{(\mathrm{Al}-\mathrm{Zn})}=-f_{\mathrm{Zn}}^{(\mathrm{Al})}+f_{\mathrm{Zn}}^{(\mathrm{Zn})}=-\frac{(W-1)\left(W-W_{\mathrm{Sn}}\right)\left(W-W_{\mathrm{Zn}}\right)}{\left(\mathrm{W}_{\mathrm{Zn}}-1\right)\left(W_{\mathrm{Zn}}-W_{\mathrm{Sn}}\right)\left(W_{\mathrm{Zn}}-W_{\mathrm{Al}}\right)} .
$$

- (Al-Sn)

$$
\begin{aligned}
(\mathrm{NU}-1)^{(\mathrm{Al}-\mathrm{Sn})} & =g_{\mathrm{Sn}}^{(\mathrm{Al}-\mathrm{Sn})} \Delta W_{\mathrm{Sn}}+g_{\mathrm{Zn}}^{(\mathrm{Al}-\mathrm{Sn})} \Delta W_{\mathrm{Zn}}+g_{\mathrm{Al}}^{(\mathrm{Al}-\mathrm{Sn})} \Delta W_{\mathrm{Al}}+g_{\mathrm{In}}^{(\mathrm{Al}-\mathrm{Sn})} \Delta W_{\mathrm{In}} \\
& =\left(-f_{\mathrm{Sn}}^{(\mathrm{Al})}+f_{\mathrm{Sn}}^{(\mathrm{Sn})} \Delta W_{\mathrm{Sn}}-f_{\mathrm{Zn}}^{(\mathrm{Al})} \Delta W_{\mathrm{Zn}}-f_{\mathrm{Al}}^{(\mathrm{Al})} \Delta W_{\mathrm{Al}}+f_{\mathrm{In}}^{(\mathrm{Sn})} \Delta W_{\mathrm{In}}\right.
\end{aligned}
$$

where

$$
g_{\mathrm{Sn}}^{(\mathrm{Al}-\mathrm{Sn})}=-f_{\mathrm{Sn}}^{(\mathrm{Al})}+f_{\mathrm{Sn}}^{(\mathrm{Sn})}=-\frac{(W-1)\left(W-W_{\mathrm{Sn}}\right)\left(W W_{\mathrm{In}}-W W_{\mathrm{Sn}}-W_{\mathrm{Al}} W_{\mathrm{In}}+W_{\mathrm{In}} W_{\mathrm{Sn}}+W_{\mathrm{Al}} W_{\mathrm{Zn}}-W_{\mathrm{In}} W_{\mathrm{Zn}}\right)}{\left(W_{\mathrm{Sn}}-1\right)\left(W_{\mathrm{Sn}}-W_{\mathrm{Zn}}\right)\left(W_{\mathrm{Sn}}-W_{\mathrm{Al}}\right)\left(W_{\mathrm{In}}-W_{\mathrm{Sn}}\right)}
$$

- (Al-In)

$$
\begin{aligned}
(\mathrm{NU}-1)^{(\mathrm{Al}-\mathrm{In})} & =g_{\mathrm{Sn}}^{(\mathrm{Al}-\mathrm{In})} \Delta W_{\mathrm{Sn}}+g_{\mathrm{Zn}}^{(\mathrm{Al}-\mathrm{In})} \Delta W_{\mathrm{Zn}}+g_{\mathrm{Al}}^{(\mathrm{Al}-\mathrm{In})} \Delta W_{\mathrm{Al}}+g_{\mathrm{In}}^{(\mathrm{Al}-\mathrm{In})} \Delta W_{\mathrm{In}} \\
& =-f_{\mathrm{Sn}}^{(\mathrm{Al})} \Delta W_{\mathrm{Sn}}-f_{\mathrm{Zn}}^{(\mathrm{Al})} \Delta W_{\mathrm{Zn}}-f_{\mathrm{Al}}^{(\mathrm{Al})} \Delta W_{\mathrm{Al}}+f_{\mathrm{In}}^{(\mathrm{In})} \Delta W_{\mathrm{In}}
\end{aligned}
$$


-(Al-Ga)

$$
\begin{aligned}
(\mathrm{NU}-1)^{(\mathrm{Al}-\mathrm{Ga})} & =g_{\mathrm{Sn}}^{(\mathrm{Al}-\mathrm{Ga})} \Delta W_{\mathrm{Sn}}+g_{\mathrm{Zn}}^{(\mathrm{Al}-\mathrm{Ga})} \Delta W_{\mathrm{Zn}}+g_{\mathrm{Al}}^{(\mathrm{Al}-\mathrm{Ga})} \Delta W_{\mathrm{Al}}+g_{\mathrm{Ga}}^{(\mathrm{Al}-\mathrm{Ga})} \Delta W_{\mathrm{Ga}} \\
& =-f_{\mathrm{Sn}}^{(\mathrm{Al})} \Delta W_{\mathrm{Sn}}-f_{\mathrm{Zn}}^{(\mathrm{Al})} \Delta W_{\mathrm{Zn}}-f_{\mathrm{Al}}^{(\mathrm{Al})} \Delta W_{\mathrm{Al}}+f_{\mathrm{Ga}}^{(\mathrm{Ga})} \Delta \mathrm{W}_{\mathrm{Ga}}
\end{aligned}
$$

- (Al-Hg)

$$
\begin{aligned}
(\mathrm{NU}-1)^{(\mathrm{Al}-\mathrm{Hg})} & =g_{\mathrm{Sn}}^{(\mathrm{Al}-\mathrm{Hg})} \Delta W_{\mathrm{Sn}}+g_{\mathrm{Zn}}^{(\mathrm{Al}-\mathrm{Hg})} \Delta W_{\mathrm{Zn}}+g_{\mathrm{Al}}^{(\mathrm{Al}-\mathrm{Hg})} \Delta W_{\mathrm{Al}}+g_{\mathrm{Ga}}^{(\mathrm{Al}-\mathrm{Hg})} \Delta W_{\mathrm{Ga}}+g_{\mathrm{Hg}}^{(\mathrm{Al}-\mathrm{Hg})} \Delta W_{\mathrm{Hg}} \\
& =-f_{\mathrm{Sn}}^{(\mathrm{Al})} \Delta W_{\mathrm{Sn}}-f_{\mathrm{Zn}}^{(\mathrm{Al})} \Delta W_{\mathrm{Zn}}-f_{\mathrm{Al}}^{(\mathrm{Al})} \Delta W_{\mathrm{Al}}+f_{\mathrm{Ga}}^{(\mathrm{Hg})} \Delta W_{\mathrm{Ga}}+f_{\mathrm{Hg}}^{(\mathrm{Hg})} \Delta W_{\mathrm{Hg}}
\end{aligned}
$$

- (Zn-Sn)

$$
\begin{aligned}
(\mathrm{NU}-1)^{(\mathrm{Zn}-\mathrm{Sn})} & =g_{\mathrm{Sn}}^{(\mathrm{Zn}-\mathrm{Sn})} \Delta W_{\mathrm{Sn}}+g_{\mathrm{Zn}}^{(\mathrm{Zn}-\mathrm{Sn})} \Delta W_{\mathrm{Zn}}+g_{\mathrm{In}}^{(\mathrm{Zn}-\mathrm{Sn})} \Delta W_{\mathrm{In}} \\
& =\left(-f_{\mathrm{Sn}}^{(\mathrm{Zn})}+f_{\mathrm{Sn}}^{(\mathrm{Sn})}\right) \Delta W_{\mathrm{Sn}}-f_{\mathrm{Zn}}^{(\mathrm{Zn})} \Delta W_{\mathrm{Zn}}+f_{\mathrm{In}}^{(\mathrm{Sn})} \Delta W_{\mathrm{In}}
\end{aligned}
$$

where

$$
g_{\mathrm{Sn}}^{(\mathrm{Zn}-\mathrm{Sn})}=-f_{\mathrm{Sn}}^{(\mathrm{Zn})}+f_{\mathrm{Sn}}^{(\mathrm{Sn})}=-\frac{(W-1)\left(W-W_{\mathrm{Sn}}\right)\left(W_{\mathrm{Zn}}-W_{\mathrm{In}}\right)}{\left(\mathrm{W}_{\mathrm{Sn}}-1\right)\left(W_{\mathrm{Sn}}-W_{\mathrm{Zn}}\right)\left(W_{\mathrm{Sn}}-W_{\mathrm{In}}\right)}
$$

- (Zn-In)

$$
(\mathrm{NU}-1)^{(\mathrm{Zn}-\mathrm{In})}=g_{\mathrm{Sn}}^{(\mathrm{Zn}-\mathrm{In})} \Delta W_{\mathrm{Sn}}+g_{\mathrm{Zn}}^{(\mathrm{Zn}-\mathrm{In})} \Delta W_{\mathrm{Zn}}+g_{\mathrm{In}}^{(\mathrm{Zn}-\mathrm{In})} \Delta W_{\mathrm{In}}=-f_{\mathrm{Sn}}^{(\mathrm{Zn})} \Delta W_{\mathrm{Sn}}-f_{\mathrm{Zn}}^{(\mathrm{Zn})} \Delta W_{\mathrm{Zn}}+f_{\mathrm{In}}^{(\mathrm{In})} \Delta W_{\mathrm{In}}
$$

- (Zn-Ga)

$(\mathrm{NU}-1)^{(\mathrm{Zn}-\mathrm{Ga})}=g_{\mathrm{Sn}}^{(\mathrm{Zn}-\mathrm{Ga})} \Delta W_{\mathrm{Sn}}+g_{\mathrm{Zn}}^{(\mathrm{Zn}-\mathrm{Ga})} \Delta W_{\mathrm{Zn}}+g_{\mathrm{Ga}}^{(\mathrm{Zn}-\mathrm{Ga})} \Delta W_{\mathrm{Ga}}=-f_{\mathrm{Sn}}^{(\mathrm{Zn})} \Delta W_{\mathrm{Sn}}-f_{\mathrm{Zn}}^{(\mathrm{Zn})} \Delta W_{\mathrm{Zn}}+f_{\mathrm{Ga}}^{(\mathrm{Ga})} \Delta W_{\mathrm{Ga}}$

- $(\mathrm{Zn}-\mathrm{Hg})$

$$
\begin{aligned}
(\mathrm{NU}-1)^{(\mathrm{Zn}-\mathrm{Hg})} & =g_{\mathrm{Sn}}^{(\mathrm{Zn}-\mathrm{Hg})} \Delta W_{S n}+g_{\mathrm{Zn}}^{(\mathrm{Zn}-\mathrm{Hg})} \Delta W_{\mathrm{Zn}}+g_{\mathrm{Ga}}^{(\mathrm{Zn}-\mathrm{Hg})} W_{\mathrm{Ga}}+g_{\mathrm{Hg}}^{(\mathrm{Zn}-\mathrm{Hg})} \Delta W_{\mathrm{Hg}} \\
& =-f_{\mathrm{Sn}}^{(\mathrm{Zn})} \Delta W_{\mathrm{Sn}}-f_{\mathrm{Zn}}^{(\mathrm{Zn})} \Delta W_{\mathrm{Zn}}+f_{\mathrm{Ga}}^{(\mathrm{Hg})} \Delta W_{\mathrm{Ga}}+f_{\mathrm{Hg}}^{(\mathrm{Hg})} \Delta W_{\mathrm{Hg}}
\end{aligned}
$$

- (Sn-In)

$$
\mathrm{NU}-1^{(\mathrm{Sn}-\mathrm{In})}=g_{\mathrm{Sn}}^{(\mathrm{Sn}-\mathrm{In})} \Delta W_{\mathrm{Sn}}+g_{\mathrm{In}}^{(\mathrm{Sn}-\mathrm{In})} \Delta W_{\mathrm{In}}=-f_{\mathrm{Sn}}^{(\mathrm{Sn})} \Delta W_{\mathrm{Sn}}+\left(-f_{\mathrm{In}}^{(\mathrm{Sn})}+f_{\mathrm{In}}^{(\mathrm{In})}\right) \Delta W_{\mathrm{In}}
$$

where

$$
g_{\mathrm{In}}^{(\mathrm{Sn}-\mathrm{In})}=-f_{\mathrm{In}}^{(\mathrm{Sn})}+f_{\mathrm{In}}^{(\mathrm{In})}=-\frac{(W-1)\left(W-W_{\mathrm{In}}\right)}{\left(\mathrm{W}_{\mathrm{In}}-1\right)\left(W_{\mathrm{In}}-W_{\mathrm{Sn}}\right)} .
$$

- (Sn-Ga)

$(\mathrm{NU}-1)^{(\mathrm{Sn}-\mathrm{Ga})}=\mathrm{g}_{\mathrm{Sn}}^{(\mathrm{Sn}-\mathrm{Ga})} \Delta \mathrm{W}_{\mathrm{Sn}}+g_{\mathrm{In}}^{(\mathrm{Sn}-\mathrm{Ga})} \Delta \mathrm{W}_{\mathrm{In}}+\mathrm{g}_{\mathrm{Ga}}^{(\mathrm{Sn}-\mathrm{Ga})} \Delta \mathrm{W}_{\mathrm{Ga}}=-f_{\mathrm{Sn}}^{(\mathrm{Sn})} \Delta \mathrm{W}_{S n}-f_{\mathrm{In}}^{(\mathrm{Sn})} \Delta \mathrm{W}_{\mathrm{In}}+f_{\mathrm{Ga}}^{(\mathrm{Ga})} \Delta \mathrm{W}_{\mathrm{Ga}}$

- (Sn-Hg)

$$
\begin{aligned}
(\mathrm{NU}-1)^{(\mathrm{Sn}-\mathrm{Hg})} & =\mathrm{g}_{\mathrm{Sn}}^{(\mathrm{Sn}-\mathrm{Hg})} \Delta W_{\mathrm{Sn}}+\mathrm{g}_{\mathrm{In}}^{(\mathrm{Sn}-\mathrm{Hg})} \Delta W_{\mathrm{In}}+\mathrm{g}_{\mathrm{Ga}}^{(\mathrm{Sn}-\mathrm{Hg})} \Delta W_{\mathrm{Ga}}+\mathrm{g}_{\mathrm{Hg}}^{(\mathrm{Sn}-\mathrm{Hg})} \Delta W_{\mathrm{Hg}} \\
& =-f_{\mathrm{Sn}}^{(\mathrm{Sn})} \Delta W_{\mathrm{Sn}}-f_{\mathrm{In}}^{(\mathrm{Sn})} \Delta W_{\mathrm{In}}+f_{\mathrm{Ga}}^{(\mathrm{Hg})} \Delta W_{\mathrm{Ga}}+f_{\mathrm{Hg}}^{(\mathrm{Hg})} \Delta W_{\mathrm{Hg}}
\end{aligned}
$$

- (In-Ga)

$$
(\mathrm{NU}-1)^{(\mathrm{In}-\mathrm{Ga})}=g_{\mathrm{In}}^{(\mathrm{In}-\mathrm{Ga})} \Delta W_{\mathrm{In}}+g_{\mathrm{Ga}}^{(\mathrm{In}-\mathrm{Ga})} \Delta W_{\mathrm{Ga}}=-f_{\mathrm{In}}^{(\mathrm{In})} \Delta W_{\mathrm{In}}+f_{\mathrm{Ga}}^{(\mathrm{Ga})} \Delta W_{\mathrm{Ga}}
$$


- (In-Hg)

$$
(\mathrm{NU}-1)^{(\mathrm{In}-\mathrm{Hg})}=g_{\mathrm{In}}^{(\mathrm{In}-\mathrm{Hg})} \Delta W_{\mathrm{In}}+g_{\mathrm{Ga}}^{(\mathrm{In}-\mathrm{Hg})} \Delta W_{\mathrm{Ga}}+g_{\mathrm{Hg}}^{(\mathrm{In}-\mathrm{Hg})} \Delta W_{\mathrm{Hg}}=-f_{\mathrm{In}}^{(\mathrm{In})} \Delta W_{\mathrm{In}}+f_{\mathrm{Ga}}^{(\mathrm{Hg})} \Delta W_{\mathrm{Ga}}+f_{\mathrm{Hg}}^{(\mathrm{Hg})} \Delta W_{\mathrm{Hg}}
$$

- $(\mathrm{Ga}-\mathrm{Hg})$

$$
(\mathrm{NU}-1)^{(\mathrm{Ga}-\mathrm{Hg})}=g_{\mathrm{Ga}}^{(\mathrm{Ga}-\mathrm{Hg})} \Delta W_{\mathrm{Ga}}+\mathrm{g}_{\mathrm{Hg}}^{(\mathrm{Ga}-\mathrm{Hg})} \Delta W_{\mathrm{Hg}}=\left(-\mathrm{f}_{\mathrm{Ga}}^{(\mathrm{Ga})}+\mathrm{f}_{\mathrm{Ga}}^{(\mathrm{Hg})}\right) \Delta W_{\mathrm{Ga}}+\mathrm{f}_{\mathrm{Hg}}^{(\mathrm{Hg})} \Delta W_{\mathrm{Hg}}
$$

where

$$
g_{\mathrm{Ga}}^{(\mathrm{Ga}-\mathrm{Hg})}=-f_{\mathrm{Ga}}^{(\mathrm{Ga})}+f_{\mathrm{Ga}}^{(\mathrm{Hg})}=\frac{(W-1)\left(W-W_{\mathrm{Ga}}\right)}{\left(\mathrm{W}_{\mathrm{Ga}}-1\right)\left(W_{\mathrm{Ga}}-W_{\mathrm{Hg}}\right)}
$$

\section{A.3 The Corrections $C_{\mathrm{NU}-1}$}

\section{- Region 1}

$$
\begin{aligned}
& C_{\mathrm{NU}-1}^{(\mathrm{Al})}=\frac{5 f_{\mathrm{Al}}^{(\mathrm{Al})} \Delta W_{\mathrm{Al}}+\left(5 f_{\mathrm{Zn}}^{(\mathrm{Al})}-f_{\mathrm{Zn}}^{(\mathrm{Zn})}\right) \Delta W_{\mathrm{Zn}}+\left(5 f_{\mathrm{Sn}}^{(\mathrm{Al})}-f_{\mathrm{Sn}}^{(\mathrm{Zn})}-f_{\mathrm{Sn}}^{(\mathrm{Sn})}\right) \Delta W_{\mathrm{Sn}}}{6} \\
& +\frac{\left(-f_{\mathrm{In}}^{(\mathrm{Sn})}-f_{\mathrm{In}}^{(\mathrm{In})}\right) \Delta W_{\mathrm{In}}+\left(-f_{\mathrm{Ga}}^{(\mathrm{Ga})}-f_{\mathrm{Ga}}^{(\mathrm{Hg})}\right) \Delta W_{\mathrm{Ga}}-f_{\mathrm{Hg}}^{(\mathrm{Hg})} \Delta W_{\mathrm{Hg}}}{6} \\
& C_{\mathrm{NU}-1}^{(\mathrm{Zn})}=\frac{-f_{\mathrm{Al}}^{(\mathrm{Al})} \Delta W_{\mathrm{Al}}+\left(-f_{\mathrm{Zn}}^{(\mathrm{Al})}+5 f_{\mathrm{Zn}}^{(\mathrm{Zn})}\right) \Delta W_{\mathrm{Zn}}+\left(-f_{\mathrm{Sn}}^{(\mathrm{Al})}+5 f_{\mathrm{Sn}}^{(\mathrm{Zn})}-f_{\mathrm{Sn}}^{(\mathrm{Sn})}\right) \Delta W_{\mathrm{Sn}}}{6} \\
& +\frac{\left(-f_{\mathrm{In}}^{(\mathrm{Sn})}-f_{\mathrm{In}}^{(\mathrm{In})}\right) \Delta W_{\mathrm{In}}+\left(-f_{\mathrm{Ga}}^{(\mathrm{Ga})}-f_{\mathrm{Ga}}^{(\mathrm{Hg})}\right) \Delta W_{\mathrm{Ga}}-f_{\mathrm{Hg}}^{(\mathrm{Hg})} \Delta W_{\mathrm{Hg}}}{6} \\
& C_{\mathrm{NU}-1}^{(\mathrm{Sn})}=\frac{-f_{\mathrm{Al}}^{(\mathrm{Al})} \Delta W_{\mathrm{Al}}+\left(-f_{\mathrm{Zn}}^{(\mathrm{Al})}-f_{\mathrm{Zn}}^{(\mathrm{Zn})}\right) \Delta W_{\mathrm{Zn}}+\left(-f_{\mathrm{Sn}}^{(\mathrm{Al})}-f_{\mathrm{Sn}}^{(\mathrm{Zn})}+5 f_{\mathrm{Sn}}^{(\mathrm{Sn})}\right) \Delta W_{\mathrm{Sn}}}{6} \\
& +\frac{\left(+5 f_{\mathrm{In}}^{(\mathrm{Sn})}-f_{\mathrm{In}}^{(\mathrm{In})}\right) \Delta W_{\mathrm{In}}+\left(-f_{\mathrm{Ga}}^{(\mathrm{Ga})}-f_{\mathrm{Ga}}^{(\mathrm{Hg})}\right) \Delta W_{\mathrm{Ga}}-f_{\mathrm{Hg}}^{(\mathrm{Hg})} \Delta W_{\mathrm{Hg}}}{6} \\
& C_{\mathrm{NU}-1}^{(\mathrm{In})}=\frac{-f_{\mathrm{Al}}^{(\mathrm{Al})} \Delta W_{\mathrm{Al}}+\left(-f_{\mathrm{Zn}}^{(\mathrm{Al})}-f_{\mathrm{Zn}}^{(\mathrm{Zn})}\right) \Delta W_{\mathrm{Zn}}+\left(-f_{\mathrm{Sn}}^{(\mathrm{Al})}-f_{\mathrm{Sn}}^{(\mathrm{Zn})}-f_{\mathrm{Sn}}^{(\mathrm{Sn})}\right) \Delta W_{\mathrm{Sn}}}{6} \\
& +\frac{\left(-f_{\mathrm{In}}^{(\mathrm{Sn})}+5 f_{\mathrm{In}}^{(\mathrm{In})}\right) \Delta W_{\mathrm{In}}+\left(-f_{\mathrm{Ga}}^{(\mathrm{Ga})}-f_{\mathrm{Ga}}^{(\mathrm{Hg})}\right) \Delta W_{\mathrm{Ga}}-f_{\mathrm{Hg}}^{(\mathrm{Hg})} \Delta W_{\mathrm{Hg}}}{6} \\
& C_{\mathrm{NU}-1}^{(\mathrm{Ga})}=\frac{-f_{\mathrm{Al}}^{(\mathrm{Al})} \Delta W_{\mathrm{Al}}+\left(-f_{\mathrm{Zn}}^{(\mathrm{Al})}-f_{\mathrm{Zn}}^{(\mathrm{Zn})}\right) \Delta W_{\mathrm{Zn}}+\left(-f_{\mathrm{Sn}}^{(\mathrm{Al})}-f_{\mathrm{Sn}}^{(\mathrm{Zn})}-f_{\mathrm{Sn}}^{(\mathrm{Sn})}\right) \Delta W_{\mathrm{Sn}}}{6} \\
& +\frac{\left(-f_{\mathrm{In}}^{(\mathrm{Sn})}-f_{\mathrm{In}}^{(\mathrm{In})}\right) \Delta W_{\mathrm{In}}+\left(5 f_{\mathrm{Ga}}^{(\mathrm{Ga})}-f_{\mathrm{Ga}}^{(\mathrm{Hg})}\right) \Delta W_{\mathrm{Ga}}-f_{\mathrm{Hg}}^{(\mathrm{Hg})} \Delta W_{\mathrm{Hg}}}{6} \\
& C_{\mathrm{NU}-1}^{(\mathrm{Hg})}=\frac{-f_{\mathrm{Al}}^{(\mathrm{Al})} \Delta W_{\mathrm{Al}}+\left(-f_{\mathrm{Zn}}^{(\mathrm{Al})}-f_{\mathrm{Zn}}^{(\mathrm{Zn})}\right) \Delta W_{\mathrm{Zn}}+\left(-f_{\mathrm{Sn}}^{(\mathrm{Al})}-f_{\mathrm{Sn}}^{(\mathrm{Zn})}-f_{\mathrm{Sn}}^{(\mathrm{Sn})}\right) \Delta W_{\mathrm{Sn}}}{6} \\
& +\frac{\left(-f_{\mathrm{In}}^{(\mathrm{Sn})}-f_{\mathrm{In}}^{(\mathrm{In})}\right) \Delta W_{\mathrm{In}}+\left(-f_{\mathrm{Ga}}^{(\mathrm{Ga})}+5 f_{\mathrm{Ga}}^{(\mathrm{Hg})}\right) \Delta W_{\mathrm{Ga}}+5 f_{\mathrm{Hg}}^{(\mathrm{Hg})} \Delta W_{\mathrm{Hg}}}{6}
\end{aligned}
$$

\section{- Region 2}

$$
C_{\mathrm{NU}-1}^{(\mathrm{Al})}=\frac{3 f_{\mathrm{Al}}^{(\mathrm{Al})} \Delta W_{\mathrm{Al}}+\left(3 f_{\mathrm{Zn}}^{(\mathrm{Al})}-f_{\mathrm{Zn}}^{(\mathrm{Zn})}\right) \Delta W_{\mathrm{Zn}}+\left(3 f_{\mathrm{Sn}}^{(\mathrm{Al})}-f_{\mathrm{Sn}}^{(\mathrm{Zn})}-f_{\mathrm{Sn}}^{(\mathrm{Sn})}\right) \Delta W_{\mathrm{Sn}}+\left(-f_{\mathrm{In}}^{(\mathrm{Sn})}-f_{\mathrm{In}}^{(\mathrm{In})}\right) \Delta W_{\mathrm{In}}}{4}
$$




$$
\begin{gathered}
C_{\mathrm{NU}-1}^{(\mathrm{Zn})}=\frac{-f_{\mathrm{Al}}^{(\mathrm{Al})} \Delta W_{\mathrm{Al}}+\left(-f_{\mathrm{Zn}}^{(\mathrm{Al})}+3 f_{\mathrm{Zn}}^{(\mathrm{Zn})}\right) \Delta W_{\mathrm{Zn}}+\left(-f_{\mathrm{Sn}}^{(\mathrm{Al})}+3 f_{\mathrm{Sn}}^{(\mathrm{Zn})}-f_{\mathrm{Sn}}^{(\mathrm{Sn})}\right) \Delta W_{\mathrm{Sn}}+\left(-f_{\mathrm{In}}^{(\mathrm{Sn})}-f_{\mathrm{In}}^{(\mathrm{In})}\right) \Delta W_{\mathrm{In}}}{4} \\
C_{\mathrm{NU}-1}^{(\mathrm{Sn})}=\frac{-f_{\mathrm{Al}}^{(\mathrm{Al})} \Delta W_{\mathrm{Al}}+\left(-f_{\mathrm{Zn}}^{(\mathrm{Al})}-f_{\mathrm{Zn}}^{(\mathrm{Zn})}\right) \Delta W_{\mathrm{Zn}}+\left(-f_{\mathrm{Sn}}^{(\mathrm{Al})}-f_{\mathrm{Sn}}^{(\mathrm{Zn})}+3 f_{\mathrm{Sn}}^{(\mathrm{Sn})}\right) \Delta W_{\mathrm{Sn}}+\left(3 f_{\mathrm{In}}^{(\mathrm{Sn})}-f_{\mathrm{In}}^{(\mathrm{In})}\right) \Delta W_{\mathrm{In}}}{4} \\
C_{\mathrm{NU}-1}^{(\mathrm{In})}=\frac{-f_{\mathrm{Al}}^{(\mathrm{Al})} \Delta W_{\mathrm{Al}}+\left(-f_{\mathrm{Zn}}^{(\mathrm{Al})}-f_{\mathrm{Zn}}^{(\mathrm{Zn})}\right) \Delta W_{\mathrm{Zn}}+\left(-f_{\mathrm{Sn}}^{(\mathrm{Al})}-f_{\mathrm{Sn}}^{(\mathrm{Zn})}-f_{\mathrm{Sn}}^{(\mathrm{Sn})}\right) \Delta W_{\mathrm{Sn}}+\left(-f_{\mathrm{In}}^{(\mathrm{Sn})}+3 f_{\mathrm{In}}^{(\mathrm{In})}\right) \Delta W_{\mathrm{In}}}{4}
\end{gathered}
$$

- Region 3

$$
\begin{gathered}
C_{\mathrm{NU}-1}^{(\mathrm{Al})}=\frac{2 f_{\mathrm{Al}}^{(\mathrm{Al})} \Delta W_{\mathrm{Al}}+\left(2 f_{\mathrm{Zn}}^{(\mathrm{Al})}-f_{\mathrm{Zn}}^{(\mathrm{Zn})}\right) \Delta W_{\mathrm{Zn}}+\left(2 f_{\mathrm{Sn}}^{(\mathrm{Al})}-f_{\mathrm{Sn}}^{(\mathrm{Zn})}-f_{\mathrm{Sn}}^{(\mathrm{Sn})}\right) \Delta W_{\mathrm{Sn}}-f_{\mathrm{In}}^{(\mathrm{Sn})} \Delta W_{\mathrm{In}}}{3} \\
C_{\mathrm{NU}-1}^{(\mathrm{Zn})}=\frac{-f_{\mathrm{Al}}^{(\mathrm{Al})} \Delta W_{\mathrm{Al}}+\left(-f_{\mathrm{Zn}}^{(\mathrm{Al})}+2 f_{\mathrm{Zn}}^{(\mathrm{Zn})}\right) \Delta W_{\mathrm{Zn}}+\left(-f_{\mathrm{Sn}}^{(\mathrm{Al})}+2 f_{\mathrm{Sn}}^{(\mathrm{Zn})}-f_{\mathrm{Sn}}^{(\mathrm{Sn})}\right) \Delta W_{\mathrm{Sn}}-f_{\mathrm{In}}^{(\mathrm{Sn})} \Delta W_{\mathrm{In}}}{3} \\
C_{\mathrm{NU}-1}^{(\mathrm{Sn})}=\frac{-f_{\mathrm{Al}}^{(\mathrm{Al})} \Delta W_{\mathrm{Al}}+\left(-f_{\mathrm{Zn}}^{(\mathrm{Al})}-f_{\mathrm{Zn}}^{(\mathrm{Zn})}\right) \Delta W_{\mathrm{Zn}}+\left(-f_{\mathrm{Sn}}^{(\mathrm{Al})}-f_{\mathrm{Sn}}^{(\mathrm{Zn})}+2 f_{\mathrm{Sn}}^{(\mathrm{Sn})}\right) \Delta W_{\mathrm{Sn}}+2 f_{\mathrm{In}}^{(\mathrm{Sn})} \Delta W_{\mathrm{In}}}{3}
\end{gathered}
$$

\section{- Region 4}

$$
\begin{gathered}
C_{\mathrm{NU}-1}^{(\mathrm{Al})}=\frac{f_{\mathrm{Al}}^{(\mathrm{Al})} \Delta W_{\mathrm{Al}}+\left(f_{\mathrm{Zn}}^{(\mathrm{Al})}-f_{\mathrm{Zn}}^{(\mathrm{Zn})}\right) \Delta W_{\mathrm{Zn}}+\left(f_{\mathrm{Sn}}^{(\mathrm{Al})}-f_{\mathrm{Sn}}^{(\mathrm{Zn})}\right) \Delta W_{\mathrm{Sn}}}{2} . \\
C_{\mathrm{NU}-1}^{(\mathrm{Zn})}=\frac{-f_{\mathrm{Al}}^{(\mathrm{Al})} \Delta W_{\mathrm{Al}}+\left(-f_{\mathrm{Zn}}^{(\mathrm{Al})}+f_{\mathrm{Zn}}^{(\mathrm{Zn})}\right) \Delta W_{\mathrm{Zn}}+\left(-f_{\mathrm{Sn}}^{(\mathrm{Al})}+f_{\mathrm{Sn}}^{(\mathrm{Zn})}\right) \Delta W_{\mathrm{Sn}}}{2} .
\end{gathered}
$$




\section{Appendix B: Additional figures}

\section{(Al)}

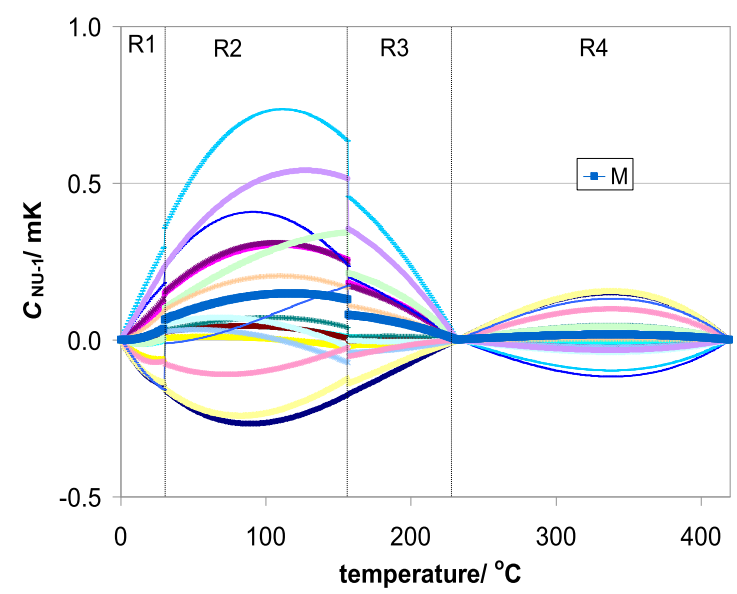

$(\mathrm{Sn})$

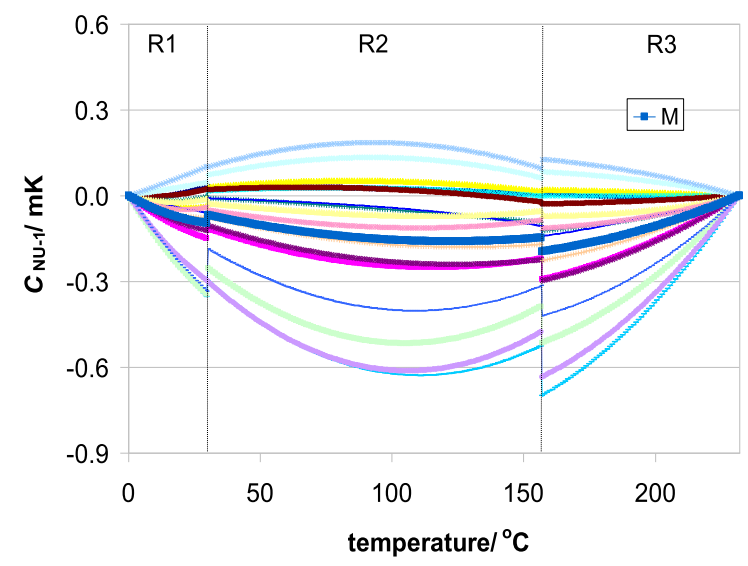

(Ga)

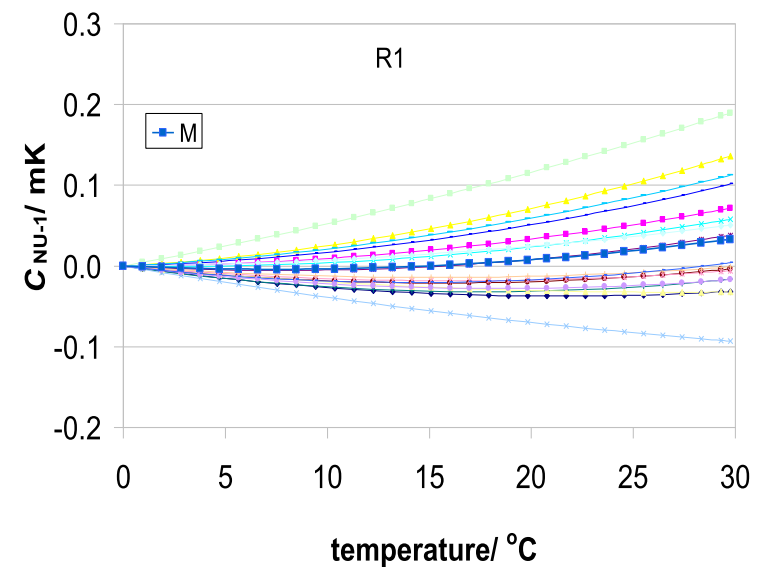

$(\mathrm{Zn})$

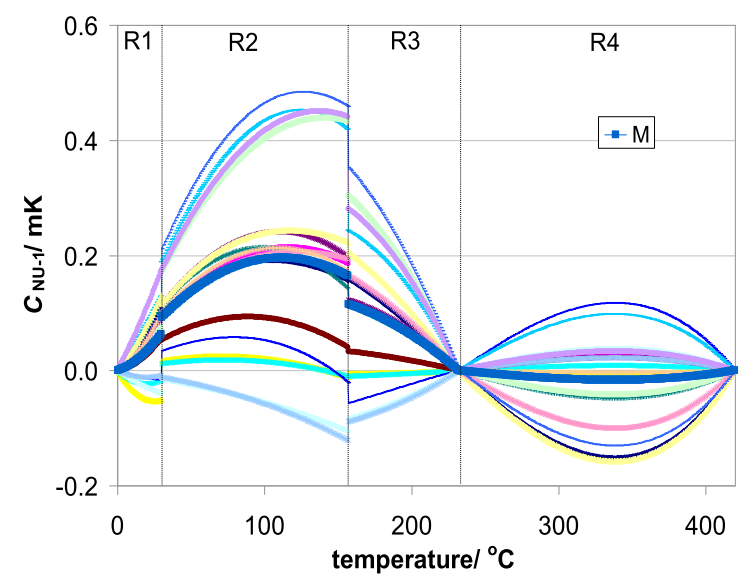

(In)

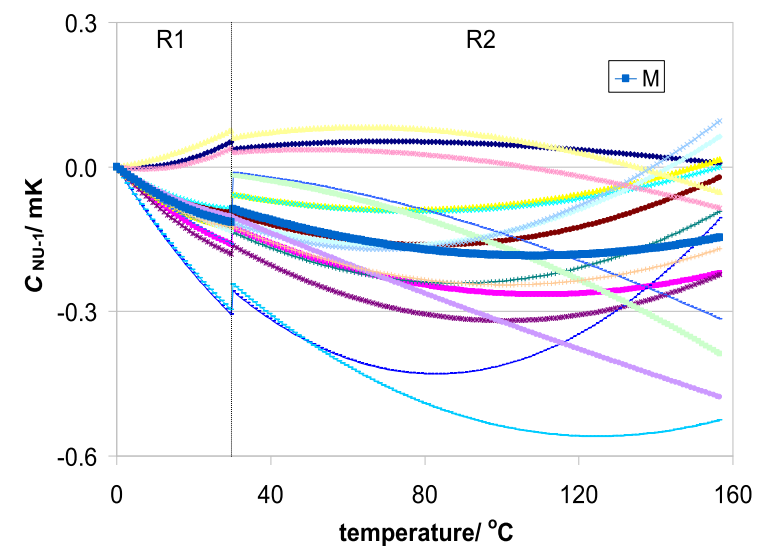

(Hg)

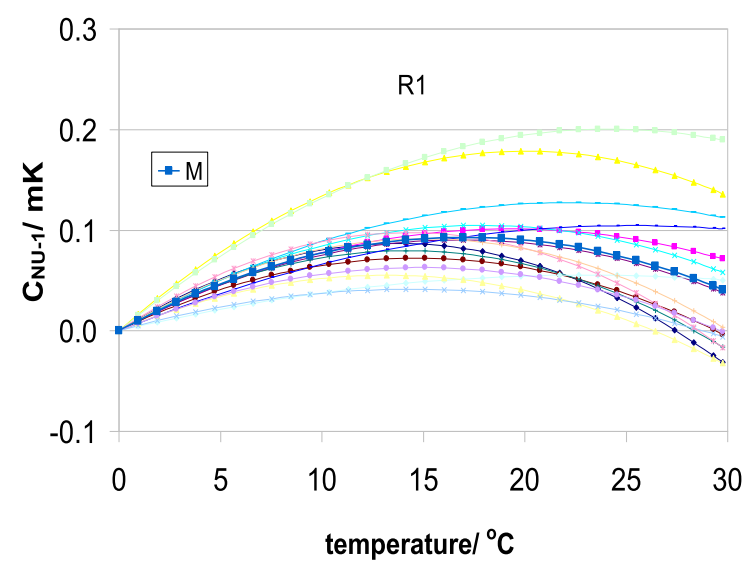

Fig. B.1. Correction $C_{\mathrm{NU}-1}$ versus temperature for the 6 subranges under analysis: $(\mathrm{Al}),(\mathrm{Zn}),(\mathrm{Sn}),(\mathrm{In}),(\mathrm{Ga})$, and (Hg). The vertical lines on each chart mark the regions of temperature, with $6,4,3$ and, respectively, 2 overlapping subranges $(\mathrm{R} i, i=1,2,3,4)$. 

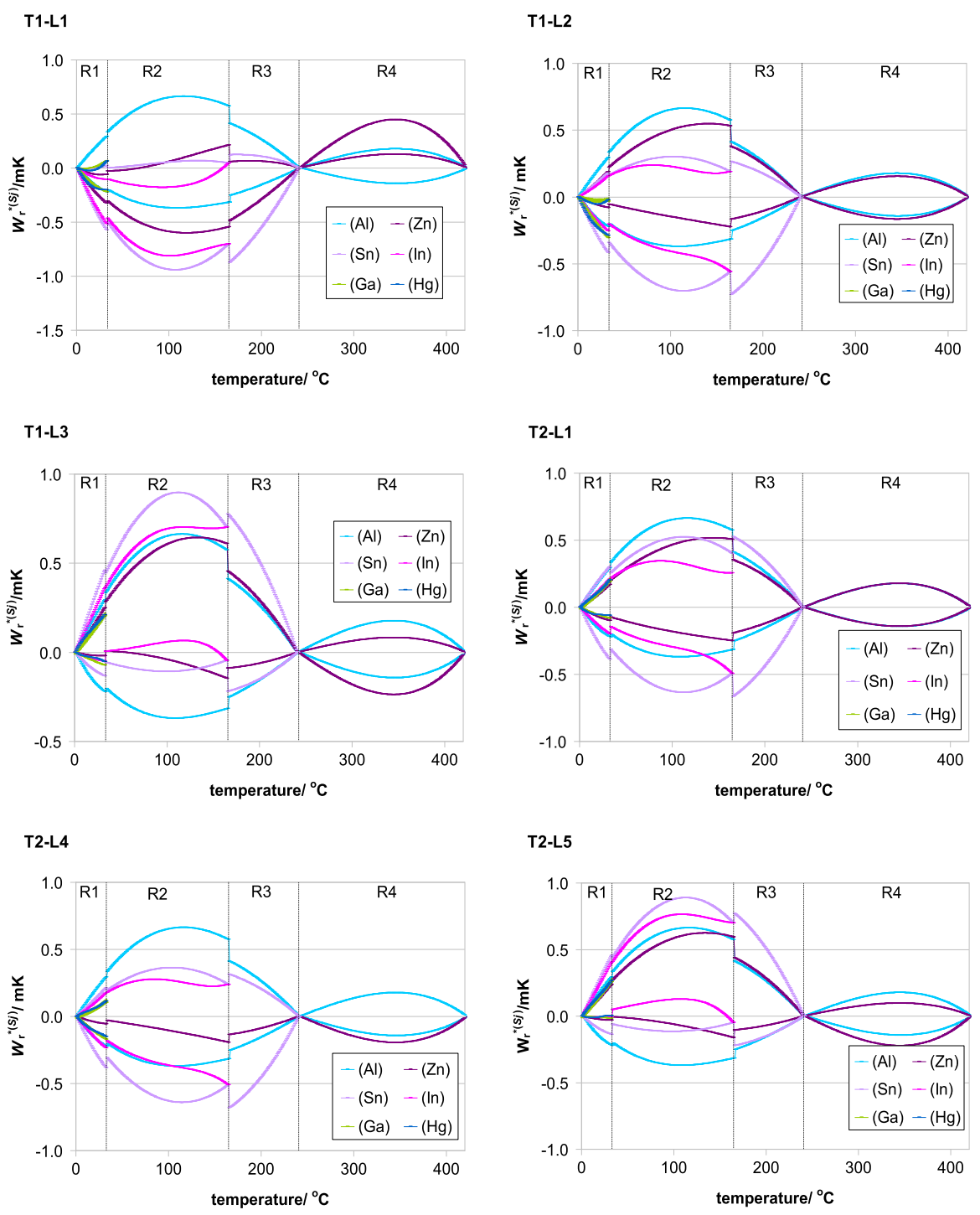

Fig. B.2. We have graphically verified the consistency of the corrected results obtained in the different subranges that overlap. The values of $W_{\mathrm{r}, \text { corrected }}=W_{\mathrm{r}}^{(S j)}+C_{\mathrm{NU}-1}^{(S j)}$ in each subrange $(S j)$ are several orders of magnitude higher than the values of the applied corrections. For this reason, before drawing the diagrams, we resorted to shifting each value $W_{r}^{(S j)}+C_{\mathrm{NU}-1}^{(S j)}$ by the same quantity, namely $-W_{r}^{(\mathrm{Al})}$, an adjustment that does not affect the validity of the test. The corrected (and adjusted) result $W_{r}^{*(S j)}$ then becomes

$W_{r}^{*(S j)}=\left(W_{r}^{(\mathrm{Sj})}-W_{r}^{(\mathrm{Al})}\right)+M_{\mathrm{NU}-1}^{(S j)} \pm U=\left(W_{r}^{(\mathrm{Sj})}-W_{r}^{(\mathrm{Al})}\right)+M_{\mathrm{NU}-1}^{(S j)} \pm k u\left(C_{\mathrm{NU}-1}^{(S j)}\right)$,

where

- the difference $\left(W_{r}^{(\mathrm{Sj})}-W_{r}^{(\mathrm{Al})}\right)$ is considered to be a number without uncertainty,

$-M_{\mathrm{NU}-1}^{(S j)}$ is the sample mean,

- $U$ is the extended uncertainty, $-U=k u\left(C_{\mathrm{NU}-1}^{(S j)}\right)$, which defines an interval having a level of confidence of approximately $95 \%$ for a normal distribution, with the standard uncertainty $u\left(C_{\mathrm{NU}-1}^{(S j)}\right)=s\left(C_{\mathrm{NU}-1}^{(S j)}\right)$ and $k=2$.

The graphics created for the corrected results $W_{r}^{*(S j)}$ vs temperature demonstrate that the intervals of uncertainty overlap in all cases. By consequence, we can claim that the results obtained after the correction in the different subranges that overlap are consistent (they agree) within their uncertainties (calculated for a level of confidence of $95 \%$ ) [31,32].

The vertical lines on each chart mark the regions of temperature, with $6,4,3$ and, respectively, 2 overlapping subranges (R $i, i=1,2,3$, 4). L - participating laboratory; T - calibrated thermometer. 

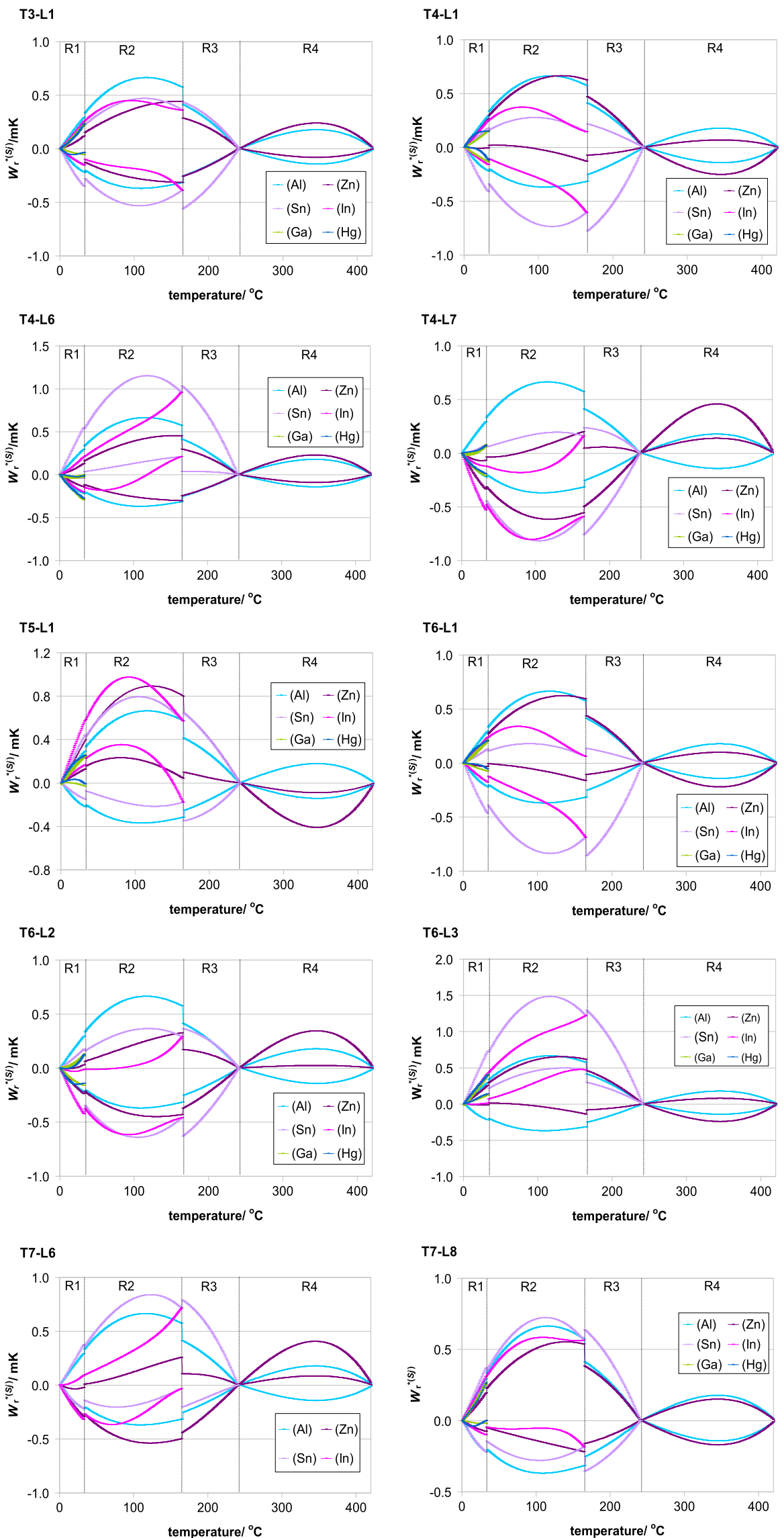

\section{T7-L8}

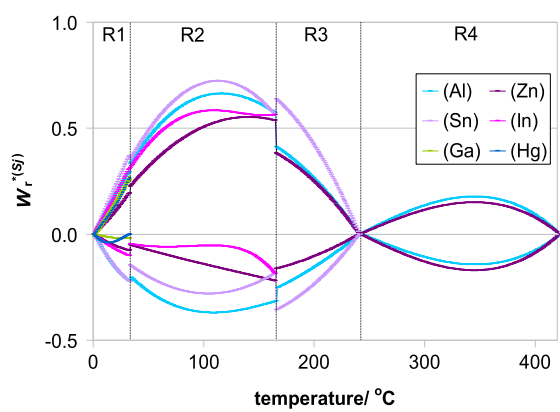

Fig. B.2. (Continued) 
(Al-Zn)

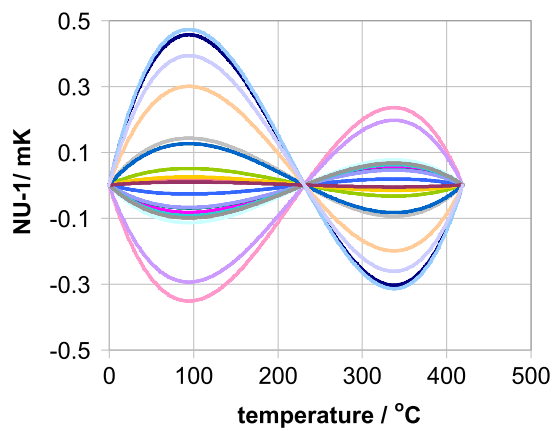

(AI-In)

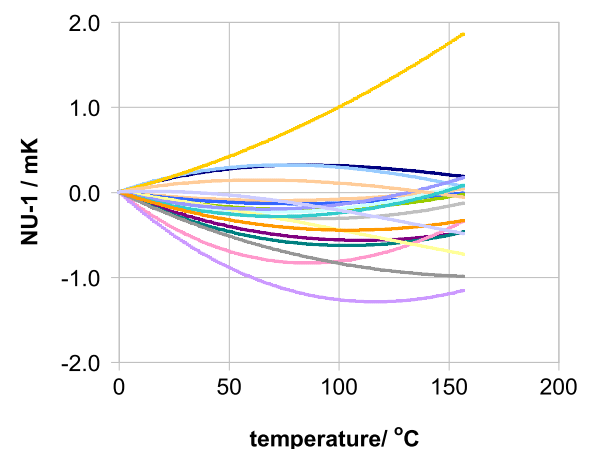

(Al-Hg)

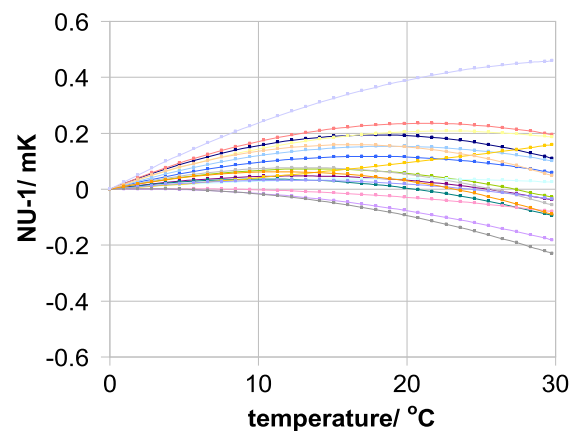

(Zn-In)

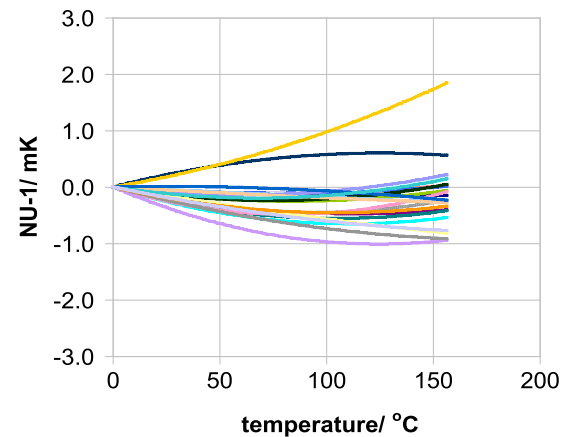

(Al-Sn)

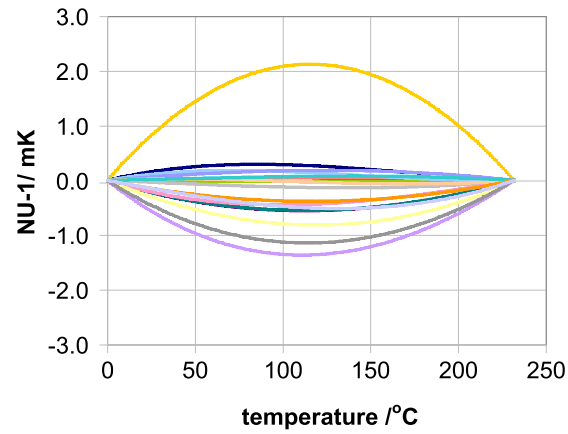

(Al-Ga)

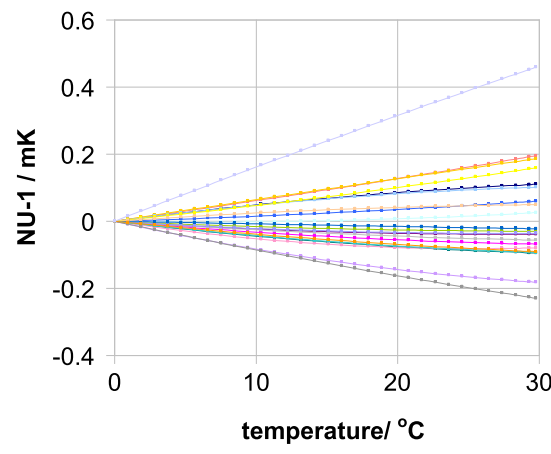

(Zn-Sn)

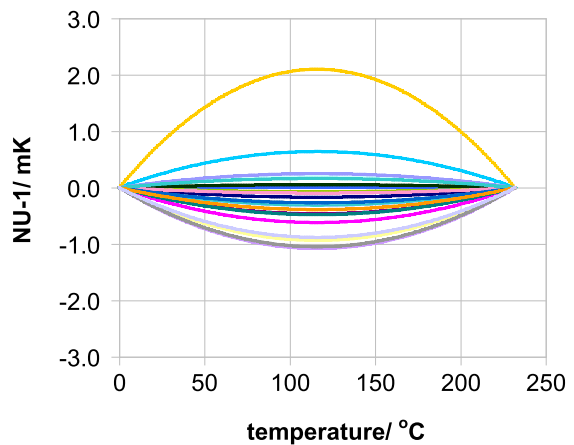

(Zn-Ga)

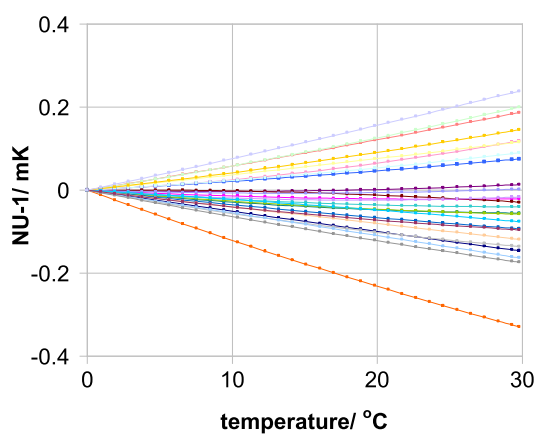

Fig. B.3. The Simple Type 1 non-uniqueness vs temperature for the 15 pairs of overlapping subranges under analysis: (Al-Zn); (Al$\mathrm{Sn}) ;(\mathrm{Al}-\mathrm{In}) ;(\mathrm{Al}-\mathrm{Ga}) ;(\mathrm{Al}-\mathrm{Hg}) ;(\mathrm{Zn}-\mathrm{Sn}) ;(\mathrm{Zn}-\mathrm{In}) ;(\mathrm{Zn}-\mathrm{Ga}) ;(\mathrm{Zn}-\mathrm{Hg}) ;(\mathrm{Sn}-\mathrm{In}) ;(\mathrm{Sn}-\mathrm{Ga}) ;(\mathrm{Sn}-\mathrm{Hg}) ;(\mathrm{In}-\mathrm{Ga}) ;(\mathrm{In}-\mathrm{Hg}) ;(\mathrm{Ga}-\mathrm{Hg})$. 

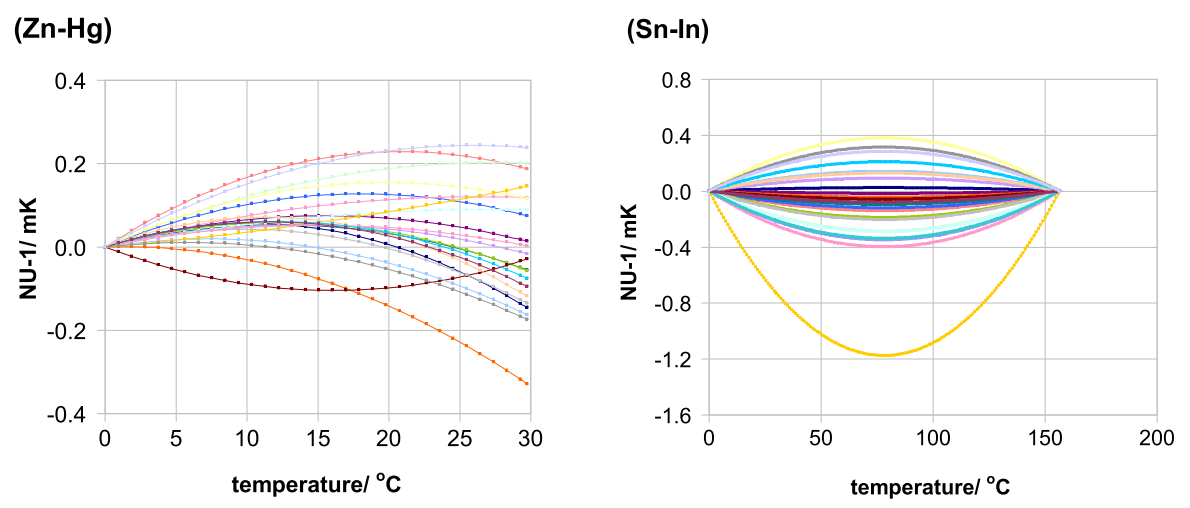

\section{(Sn-Ga)}

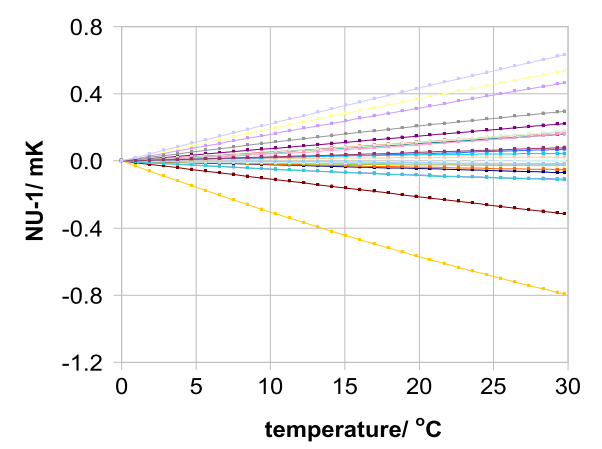

(Sn-Hg)
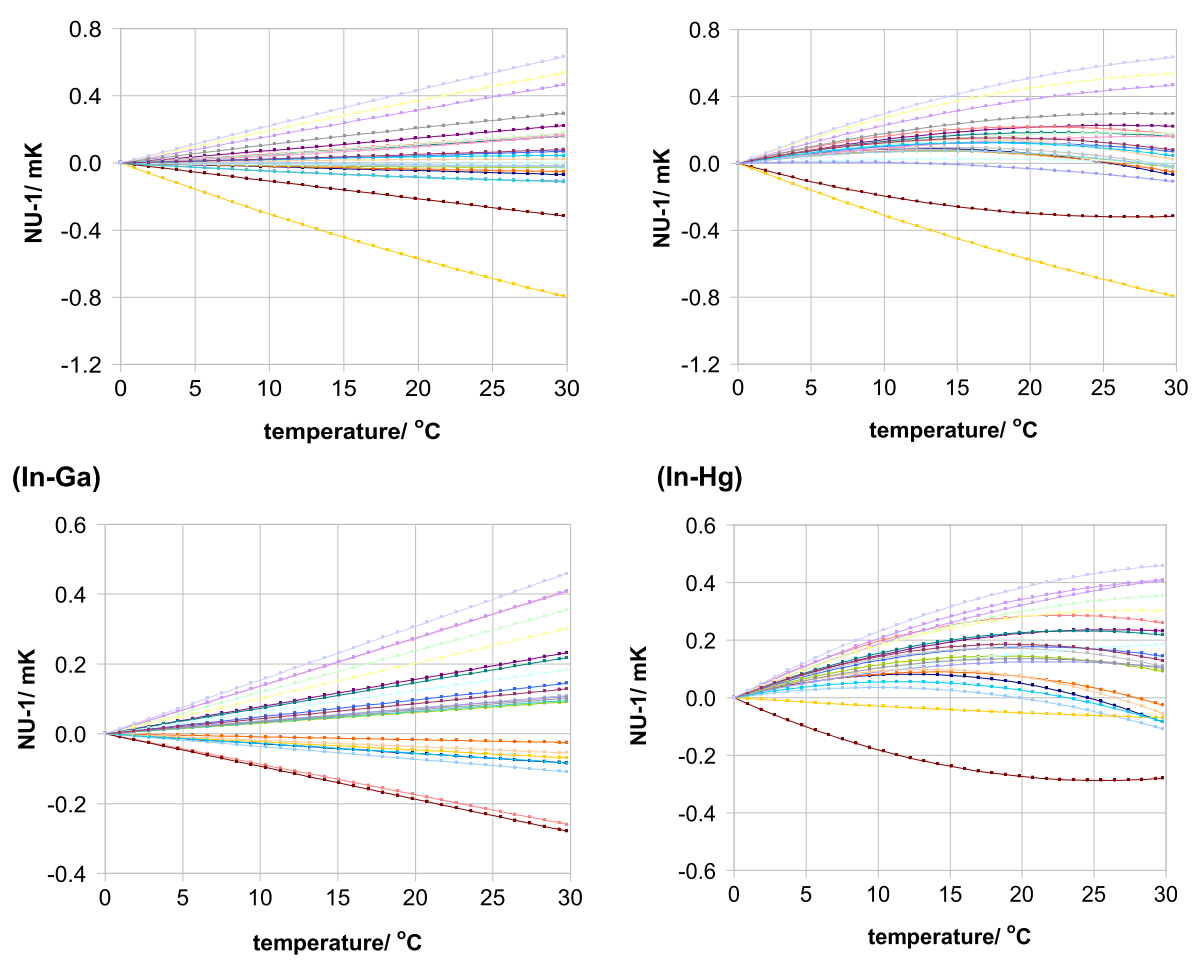

\section{(Ga-Hg)}

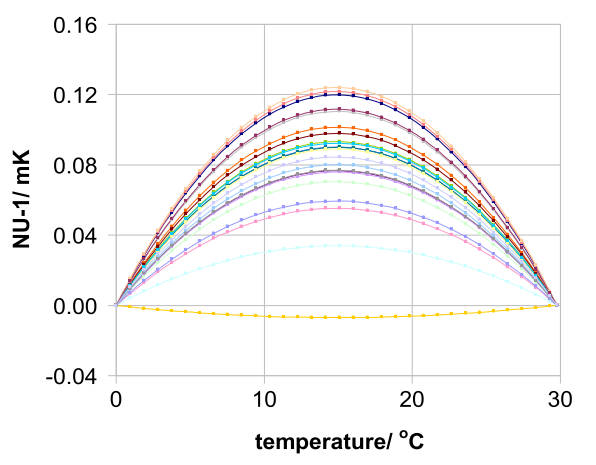

Fig. B.3. (Continued) 